WellBeing International

WBI Studies Repository

6-2001

\title{
Mammalian Play: Training for the Unexpected
}

\author{
Marek Špinka \\ Research Institute of Animal Production \\ Ruth C. Newberry \\ Washington State University \\ Marc Bekoff \\ University of Colorado
}

Follow this and additional works at: https://www.wellbeingintlstudiesrepository.org/acwp_ena

Part of the Animal Studies Commons, Behavior and Ethology Commons, and the Comparative Psychology Commons

\section{Recommended Citation}

Spinka, M., Newberry, R. C., \& Bekoff, M. (2001). Mammalian play: training for the unexpected. Quarterly Review of Biology, 141-168.

This material is brought to you for free and open access by WellBeing International. It has been accepted for inclusion by an authorized administrator of the WBI Studies Repository. For more information, please contact wbisr-info@wellbeingintl.org.

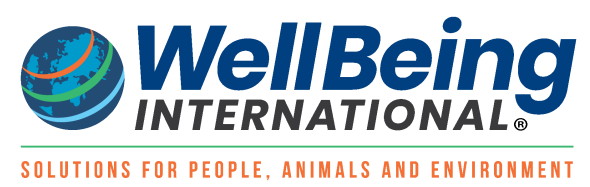




\title{
The Quarterly Review of BIOLOGY

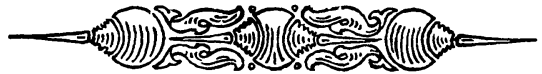

\section{MAMMALIAN PLAY: TRAINING FOR THE UNEXPECTED}

\author{
MAREK ŠPINKA \\ Ethology Group, Research Institute of Animal Production \\ CZ-104 01 Prague-Uhřněves, Czech Republic \\ E-MAIL: SPINKA@VUZV.CZ
}

\section{Ruth C. NewberRy}

Center for the Study of Animal Welfare, Washington State University

Pullman, Washington 99164-6520 USA

E-MAIL: RNEWBERRY@WSU.EDU

\begin{abstract}
MARC BEKOFF
Department of Environmental, Population, and Organismic Biology, University of Colorado Boulder, Colorado 80309-0334 USA

E-MAIL: MARC.BEKOFF@COLORADO.EDU
\end{abstract}

ABSTRACT

In this review, we present a new conceptual framework for the study of play behavior, a hitherto puzzling array of seemingly purposeless and unrelated behavioral elements that are recognizable as play throughout the mammalian lineage. Our major new functional hypothesis is that play enables animals to develop flexible kinematic and emotional responses to unexpected events in which they experience a sudden loss of control. Specifically, we propose that play functions to increase the versatility of movements used to recover from sudden shocks such as loss of balance and falling over, and to enhance the ability of animals to cope emotionally with unexpected stressful situations. To obtain this "training for the unexpected," we suggest that animals actively seek and create unexpected situations in play through self-handicapping; that is, deliberately relaxing control over their movements or actively putting themselves into disadvantageous positions and situations. Thus, play is comprised of sequences in which the players switch rapidly between well-controlled move-

The Quarterly Review of Biology, June 2001, Vol. 76, No. 2

Copyright (C) 2001 by The University of Chicago. All rights reserved.

0033-5770/2001/7602-0001\$02.00 
ments similar to those used in "serious" behavior and self-handicapping movements that result in temporary loss of control. We propose that this playful switching between in-control and outof-control elements is cognitively demanding, setting phylogenetic and ontogenetic constraints on play, and is underlain by neuroendocrinological responses that produce a complex emotional state known as "having fun." Furthermore, we propose that play is often prompted by relatively novel or unpredictable stimuli, and is thus related to, although distinct from, exploration. We present 24 predictions that arise from our new theoretical framework, examining the extent to which they are supported by the existing empirical evidence and contrasting them with the predictions of four major alternative hypotheses about play. We argue that our "training for the unexpected" hypothesis can account for some previously puzzling kinematic, structural, motivational, emotional, cognitive, social, ontogenetic, and phylogenetic aspects of play. It may also account for a diversity of individual methods for coping with unexpected misfortunes.

A MAJOR AREA of interest for those who study "play behavior" centers on the questions: Why and how has play behavior evolved, and how has it been maintained in populations of different species by natural selection (Bekoff and Byers 1998; Power 2000)? There has been little success in achieving a generally valid and empirically supported answer to these questions. The extensive variability of play patterns suggests to some researchers that play may serve different functions in animals of different species, and in individuals of different ages and sex within the same species (Gomendio 1988; Bekoff and Byers 1998; Pellegrini and Smith 1998). Some authors even think that attempts to find a single function for all play behavior are doomed to failure. For instance, Burghardt (1998a) regards play as almost certainly a "heterogeneous category linked together by characteristics that may be superficially similar, but have separate origins, causes, functions, and ontogenies" ( $\mathrm{p} 22$ ).

While a pluralistic approach may be the most appropriate way to tackle questions about the specific functions of different modes of play, the implication that no comprehensive understanding of play is possible is discouraging. If play is a heterogeneous category with neither a traceable phylogenetic root nor a common function, then why study it as a general phenomenon? Would it not be better to try to split it into smaller homogeneous categories? Should we, in the end, treat play just on a case-by-case basis?

There are two reasons to reject this position. First, play behavior patterns, as diverse as they might be, do have features in common (Fagen 1981; Burghardt 1984; Bekoff and Byers 1998). In most cases, both novice and professional ethologists agree in their classification of behavior as either play or nonplay (e.g., Rasa 1984). It is easier to see the unity of play than to find any clear natural borders within the richness of play that could be used to split it into more manageable categories. Second, play is nearly ubiquitous in all mammalian orders. This suggests either a common ancestry or a similar set of selection pressures that acted in all diverging mammalian orders in the Cenozoic (Byers 1984). In our view, it is more parsimonious to assume that there is a basic phylogenetic and functional unity underlying mammalian play than to assume that the "superficially similar" play patterns widely distributed in mammals evolved independently many times during mammalian phylogeny. Hence the search for a major function of play seems to be justified and important, as it is for other widely distributed mammalian characteristics such as sleep (Tobler 1995).

In this paper, we propose a major new hypothesis about the adaptive value of play behavior, with related structural, psychological, and cognitive constituents. We follow with a set of testable predictions that arise from this theoretical framework. We then examine some previous hypotheses about the function(s) of play, contrasting their performance against that of our new hypothesis, based on how parsimoniously and consistently each hypothesis accounts for the available empirical information on mammalian play. We argue that our hypothesis can account for some well-documented kinematic, structural, motivational, emotional, cognitive, social, ontogenetic, and phylogenetic aspects of play. 


\section{The "Training For The UneXPected" Hypothesis Of Play}

THE ADAPTIVE VALUE OF PLAY

We hypothesize that a major ancestral function of play is to rehearse behavioral sequences in which animals lose full control over their locomotion, position, or sensory/spatial input and need to regain these faculties quickly. Animals learn how to improvise their behavior by chaining conventional movements with atypical movements to get themselves back into a standard position. Sequences that link highly efficient species-typical motor patterns and standard body positions with atypical movements necessary for recovery from awkward positions often occur in biologically significant situations. For example, when fleeing a predator, an animal tries to use the most efficient pattern of flight, but may be disoriented or interrupted unpredictably by rapid changes in visual input, actions of the predator, or collisions with other herd members or inanimate obstacles. The ability of the animal to recover rapidly using atypical movements could mean the difference between life and death in a predator attack. Similar mishaps may occur during intraspecific interactions and during pursuit of prey. The opponent (or the prey) adds significant unpredictability to the environment. Skilled movements often cannot be completed or properly sequenced because of interruption by the other animal.

Besides the development of locomotor versatility in unanticipated situations, we hypothesize that animals in play learn how to deal with the emotional aspect of being surprised or temporarily disoriented or disabled. Loss of control in a serious situation, despite active attempts to cope, will normally result in activation of both sympathetico-adrenomedullary and pituitary-adrenocortical systems (von Holst 1998). These systems prepare the animal for immediate action, but can have long-term costs, especially in suppressed immunocompetence (Apanius 1998). In adverse social situations, emotional overreaction may lead to undue escalation of conflicts. In the presence of a predator, emotional overreaction leading to aimless panic will decrease an animal's chance of survival. In general, adaptive responses in serious situations depend upon the animal's ability to avoid incapacitation via negative emotions. We propose that the experience of "self-induced" mishaps during play helps animals to avoid emotional overreaction during unexpected stressful situations.

The ultimate benefits obtained from play are probably low, judging from the fact that play is dropped from the behavioral time budget under harsh conditions (Baldwin and Baldwin 1974; Berger 1980; Barrett et al. 1992). However, it may be that individual differences in retaining play during harsh times were beneficial during evolution. All in all, play could probably be counted among "opportunity behaviors" (a term coined by Fraser and Duncan 1998); that is, those behaviors that bring low ultimate benefit and are therefore actuated at moments when the cost of performing them drops to an even lower level.

In short, we propose that play: (i) results in increased versatility of movements used to recover from sudden "gravitational," "kinematic," or "positional" shocks such as losing ground underfoot, falling over, being knocked over, being pinned down, or being shaken vigorously; and (ii) enhances the ability of animals to cope emotionally with unexpected situations. These may include both "locomotor" shocks as described above, and "psychological" shocks such as suddenly being faced with frightening or dangerous stimuli, unexpectedly meeting a stranger, or experiencing a sudden reversal in dominance.

SELF-HANDICAPPING - SEEKING AND GREATING THE UNEXPECTED IN PLAY

If play has the function of training for the unexpected, then unforeseen situations should occur frequently in play. We suggest that mammals actively seek and create unexpected situations in play. Specifically, we propose that mammalian play is a sequential mixture of: (a) well-controlled vigorous locomotor movements similar to those used in "serious" behavior that load heavily on fitness traits such as escape from predators, intraspecific agonism, or hunting fast or dangerous prey; and (b) movements during which postural control is compromised, or the chance for random factors to influence movement is increased so that the animal is more likely to be knocked 
off balance, fall over, lose control of a play object, or fail to counter the actions of another animal.

Animals can actively seek and create unexpected events in play through self-handicapping; that is, deliberately relaxing control over their movements or actively putting themselves into disadvantageous positions and situations. For example, animals may self-handicap by moving in a way that is less than fully stable or efficient, or by performing object manipulation while positioned in a way not best suited for full control over the object. They may also impair their sensory and spatial orientation through high-speed angular and rotatory movements of the head, putting their head into unusual positions in relation to gravity or horizon, or twisting their body in an unusual way. By using physical properties of the environment such as deep soft snow, a slippery slope, or gravity-attenuating water, animals can enhance the probability that they will be thrown off balance into unusual positions. They can also increase the probability of experiencing unexpected events by playing with or among relatively novel environmental features or among features that are moving in unpredictable ways (e.g., due to wind). In social interactions, animals can self-handicap by using positions and movements that impair their competitive ability and enable their playmates to gain the "attack" position. For example, they may inhibit the force of their bites and pushes, and allow themselves to be pushed over and chased, even when they have the ability to harm or dominate a playmate. They may also put themselves at a self-induced disadvantage by playing with larger, stronger, or more experienced play partners, or even with animals of a different species. Because play is only performed when its costs remain low, however, there is an upper limit of unpredictability and loss of control above which animals will not play.

\section{THE RELATIONSHIP BETWEEN}

EXPLORATION AND PLAY

Exploration can be viewed as a serious counterpart to play. During an initial encounter with a novel environmental feature, animals first investigate it through "serious" exploration, examining whether it is dangerous and whether it has any resource value to them. If they find the novel feature to be relatively nonthreatening, play may follow. Through their playful behavior the animals seem to address the question, "What if it really were dangerous?" Although exploration is often temporally associated with play, it differs from play in three important aspects. First, a function of exploration may be to learn how to avoid getting into trouble (by gathering information), whereas we propose that an important aim of play is to learn how to get out of trouble (through enhanced improvisation skills). Second, there is no deliberate self-handicapping in exploration. Third, whereas play is associated with a relatively relaxed and secure state, exploration is more closely associated with fear and perceived danger. If an animal loses control in play and has too much difficulty regaining it, or the situation becomes dangerous, the animal should withdraw and reassess the situation through further exploration.

\section{HAVING FUN - THE UNDERLYING EMOTION IN PLAY}

According to our hypothesis, play enables animals to develop emotional flexibility by rehearsing the emotional aspect of being surprised or temporarily disorientated or disabled. Although unexpected events that occur in a dangerous situation would likely magnify fear in inexperienced animals, we suggest that fear is modulated in play by the relatively safe context in which play occurs and the improbability that losing control will have serious consequences. In addition, regaining control following an unexpected challenge is likely to be rewarding, and the positive nature of this experience may be intensified by the rapid repetition of incontrol and out-of-control elements that occur in play. Thus, we hypothesize that play is emotionally exciting (perhaps even thrilling, though not intensely frightening) and rewarding, maybe even pleasurable, while at the same time being relaxed. We suggest that this combination of affective attributes is unique to play, producing the complex emotional state that is referred to as "having fun" in human folk psychology. We propose that the three phenomenological aspects of this "having fun" feeling are directly reflected in the kinematic, structural, and motivational character of play 
behavior. The excitement is revealed in the vigor and speed of play movements and sequences, the pleasurable aspect in the fact that animals actively seek out and work for opportunities to play, and the relaxation by the willingness of animals to self-handicap in play and play only when they are relatively safe or unstressed. It may also be that play behavior is supported by a unique pattern of neurobiological response in the brain centers associated with complex somatosensation, motor pattern control, emotionality, and reward.

\section{RICH COGNITIVE CONTENT OF PLAY}

During play, rapid alternation between controlled and uncontrolled actions requires frequent and rapid assessment and reassessment of qualitatively different situations that do not normally follow each other. This implies that play is, even when a solitary locomotor activity, a cognitively demanding activity (Allen and Bekoff 1997; Bekoff and Allen 1998). When (unpredictable) social interaction is involved, the movements, their sequencing, and, presumably, the accompanying mental states become even more complicated because the playmates change the situation with their every action. Moreover, the ability to experience the complex feeling of "having fun" may require a richly developed cognitive system. Hence, our functional hypothesis about play as training for the unexpected implies that, though such training might be advantageous for many animals, play evolved only in those with the requisite cognitive capacity. Also, the level of cognitive function needed for play may set a lower limit on the stage of ontogenetic development at which play first appears.

\section{Predictions}

FUNCTIONAL CONSEQUENGES OF PLAY

Prediction 1: The amount of play experience obtained affects the ability to physically and emotionally handle unexpected events and temporary handicaps. Animals deprived of play, be it by natural circumstances or artificial manipulation, will be less able to deal with such situations. Conversely, animals stimulated into higher-than-usual amounts of play will surpass others in their ability to cope with such situations. Evidence of improved coping may include one or more of the following: in locomotion, increased speed of balance recovery and heightened ability to regain full orientation after a collision or fall; in agonistic behavior, knowledge to avoid undue escalation, faster conflict resolution, and fewer injuries sustained; in predator-prey interactions, more effective evasive movements in response to movements of the predator, decreased chance of panic and collision with obstacles, and increased chances of escape; in response to novel physical features in the environment, a shorter latency to shift from freezing to exploration and then to play (exploiting or ignoring the feature); and when encountering unexpected situations in a serious context, a less pronounced physiological stress responseespecially in relation to the chronic elevation of adrenal glucocorticoids and compromised immunocompetence.

Prediction 2: The benefit from play towards increased locomotor versatility when handling unexpected events is most pronounced within the current phase of ontogeny, whereas the improved ability to cope emotionally with unexpected misfortunes can be both immediate and long lasting. With ongoing development, body proportions and locomotor abilities change and the body movement strategies that have been rehearsed earlier may no longer be applicable. By contrast, there is no obvious reason why increased emotional flexibility resulting from play would disappear with increasing age.

\section{KINEMATICS AND STRUCTURE OF PLAY}

Prediction 3: Self-handicapping actions are ubiquitous elements of play that frequently result in temporary loss of control. That is, play sequences in which an apparently self-handicapping action is followed immediately by being knocked off balance, slipping, falling, sliding, rolling over, losing control of a play object, or losing the "attack" orientation toward another animal are frequent. This prediction follows from our hypothesis that animals benefit from play by learning how to cope with sudden losses of control.

Prediction 4: Play is sequentially variable. Play movements that closely resemble those used in "serious" behavior such as predation, aggression, or escape are interspersed with other movements that are seemingly counterproductive towards achieving the proximate 
goal of the "serious" behavior. In addition, elements usually performed in different motivational contexts may follow each other in rapid succession during a play bout. This predicted variability is derived from our hypothesis that play enables animals to rehearse how to regain control after unexpected interruptions of normal behavioral sequences.

Prediction 5: Under favorable conditions, mammals of different species are able to play with each other, or at least stimulate each other to play. This prediction arises because certain common features of play, like performing vigorous rotational movements, moving body parts in the frontal plane, assuming asymmetrical positions, and switching between highly skilled and deliberately awkward movements, are universal and should be recognized by individuals of different species.

\section{SOCIAL ASPECTS OF PLAY}

Prediction 6: Animals prefer to play with familiar conspecifics over unfamiliar conspecifics, even if the latter are better matched in terms of body size. This is because play involves self-handicapping, which is vulnerable to cheating in animals that do not interact repeatedly with each other.

Prediction 7: Among pairs of familiar conspecifics that differ widely in body size or experience, play is more often initiated by the smaller or less experienced partner. This prediction is derived from the hypothesis that the much smaller or less experienced individual will gain a benefit from the experience of coping with being at a disadvantage in the interaction. However, if the much larger or more experienced animal is unable to self-handicap sufficiently-to lose some control and experience something unexpected from the movements of the playmate-it should terminate the interaction or fail to respond to attempts by the other individual to initiate play.

Prediction 8: When the strength or dominance status of two play partners changes, the relative degree of self-handicapping by the two individuals changes. The stronger individual will usually perform the most self-handicapping. This is because the main function of play is to train for the unexpected, not to achieve dominance over, or predate, the playmate.
Prediction 9: Play is contagious and more than two animals often interact simultaneously with each other in play. There are two reasons for this prediction. First, conspecifics at play bring much unpredictability into the environment, increasing the number of opportunities to respond to unexpected situations. Second, an animal's assessment that the current environment is sufficiently safe to engage in play is strengthened by the fact that other animals have already started to play.

Prediction 10: Play signals-elements that promote the initiation or continuation of play interaction between two or more animalsare often derived from self-handicapping actions used in play. This prediction arises from our functional hypothesis that play involving conspecifics originally served as a lesson in how to regain control in social and predatorprey interactions; thus play necessarily included vigorous species-typical actions that, when performed in a serious manner, would pose a serious threat or even immediate danger to the recipient. Hence, for play to be reciprocated, it would have been necessary to inform the recipient that these actions would be performed in a nonharmful manner. The self-handicapping movements and positions used to practice for awkward situations were good precursors for signals of an individual's playful intention. When an animal perceives another animal in a compromised position or performing a self-handicapping movement, the information that this animal cannot attack immediately is intrinsically available. An animal on its back or side cannot charge immediately, and an animal shaking its head vigorously cannot leap precisely, because its judgment of distance and direction is momentarily blurred. Play signals may also be derived from expressions, sounds, and odors associated with "having fun."

\section{NEUROPSYCHOLOGICAL MECHANISMS INVOLVED IN PLAY}

Prediction 11: Severe or prolonged negative emotions, such as fear, pain, anger, hunger, frustration, or malaise, suppress play behavior. This prediction arises from our hypothesis that play allows animals to develop adaptive responses to unexpected events without being overwhelmed by negative emotions. Clearly, 
the preexistence of overwhelming negative emotions, or their arousal during play, would be counterproductive to this process. Negative emotions are also incompatible with the "having fun" affect that is integral to play.

Prediction 12: Vigilance decreases during play. This relationship is predicted because some play movements impair the acuity of sensory input. Also, because the rapid switch between in-control and out-of-control movements and positions makes play a cognitively demanding activity, there is, presumably, little cognitive capacity left for other mental processes to occur simultaneously.

Prediction 13: There is a similarity in the neuroendocrinological basis that underlies play behavior across mammalian taxa. We predict this based on the hypothesis that the specific neurobiological processes that produce the "having fun" emotion are constitutive ancestral elements of play.

Prediction 14: Play results in measurable changes and enhancements in the brain structures that receive and integrate complex somatic sensations, control complex motor patterns, and modulate emotional reactions, whereas exploratory behavior leads, primarily, to changes in associative centers of the brain. We suggest this because, in play, the brain must deal with situations that cannot be subsumed under reliable rules but must be solved by kinematic improvisation and emotional flexibility. By contrast, exploration enables animals to gather information about regularly occurring contingencies between events.

\section{ENVIRONMENTAL CONDITIONS FOR PLAY}

Prediction 15: Members of species that typically live in stable physical habitats perform less locomotory play than members of species that typically live in more changeable physical habitats or those that move between different habitat types. This is predicted because the latter are exposed to greater environmental unpredictability, and should therefore gain a greater benefit from experience in coping with sudden environmental changes that affect locomotion. By contrast, the former should benefit more from rehearsing the specific locomotor skills needed to negotiate established routes through their territory by performing them repeatedly in a nonplayful manner (i.e., through motor learning, as described by Stamps 1995).

Prediction 16: Play increases in frequency after animals move between habitats, experience substantial changes in habitat that affect locomotion, or encounter mildly frightening or novel stimuli. Through play, animals gain experience in coping with the novel situation (e.g., snowfall in temperate and arctic regions).

Prediction 17: Play occurs only under relatively safe environmental conditions and is strongly suppressed when predators or other dangers are detected. Because play appears to produce only modest benefits, it should only occur when the costs remain low. Self-handicapping during play increases the risk of injury and predation; however, when the risk of predation is reduced by the close presence of a vigilant parent or caregiver, a large group of similar conspecifics, or a safe refuge, the probability of play should increase.

\section{ONTOGENETIC DISTRIBUTION OF PLAY}

Prediction 18: In each species of mammal, play occurs at those ages when there is the greatest danger of fitness loss if the animal is caught in an awkward situation. Older animals should play less with the physical environment because they are more familiar with it. As a result of their previous experience, the environment is more predictable and there is less need for training for the unexpected. However, play that involves social and predator-prey scenarios should continue in adults of relatively intelligent species (i.e., with high encephalization quotients: Jerison 1973; Eisenberg 1981) that adjust their strategies in response to the unpredictable behavior of intelligent conspecifics, predators, or prey.

Prediction 19: Play is most frequent and/ or intense during periods of rapid allometric growth. Rapid changes in body proportions make the control of movements less precise, resulting in more frequent misjudged actions. Hence, there should be greater benefits from playing at this time to gain practice in recovering from misjudged actions.

Prediction 20: Neonatal mammals play less than juveniles. Neonates, especially those of altricial species, lack the physical and neurological development for vigorous alternation between in-control and out-of-control posi- 
tions. Play should become more common as the animals become more capable of intentional self-handicapping.

Prediction 21: Different modes of play peak at different phases of ontogeny and, typically, a peak in locomotory play precedes a peak in social play. Mammalian conspecifics learn and adapt their behavior in response to the behavior of others; therefore the unpredictability of play interactions with conspecifics is likely to persist longer during ontogeny than the unpredictability that occurs in play stimulated by elements of the physical environment. Also, the relatively high cognitive demands of play with conspecifics may delay the peak in social play versus locomotory play.

Prediction 22: Within a population, play is expected in all juveniles of a particular age class. All juvenile mammals can gain a benefit from experience in coping with unexpected situations-not just males or the most dominant or strongest individuals.

Prediction 23: Sexual dimorphism in a particular mode of play is found in species in which the two sexes differ in how important it is to be able to cope with the types of unexpected situations that arise in that mode of play. For instance, if males engage more often in forceful agonistic interactions than females, this should be reflected in higher levels of play that enable males to train for unexpected mishaps in these interactions. In slowly maturing species, however, dimorphism in play should be related not only to behavioral dimorphism in adult life, but also (and perhaps mainly) to dimorphism in serious behavior that occurs in the current ontogenetic stage (e.g., "teasing" or showing-off behavior in juvenile or adolescent males that remain in natal herds, adolescent striving for dominance in bachelor herds). We predict that training for movement versatility has primarily immediate benefits, although benefits in terms of emotional coping can be longer lasting. It follows that, in most species, sexual dimorphism in play increases with age.

\section{PHYLOGENETIC DISTRIBUTION OF PLAY}

Prediction 24: The occurrence of play is positively correlated with the encephalization quotient (Jerison 1973; Eisenberg 1981) rather than with body mass or metabolic rate within broad taxonomic groups. This is predicted due to the cognitively demanding nature of play.

\section{Alternative Hypotheses About Play}

A wealth of explicit or implicit hypotheses about the adaptive value of play has been proposed (Bekoff and Byers 1998; Burghardt 1998b; Power 2000). Traditionally, emphasis has been placed on the development of play, because animals are usually more playful when young than as adults (but for examples of adult play, see Breuggeman 1978; Biben 1979; Fagen 1981; Zucker et al. 1986; Pellis et al. 1993; Hall 1998). Consequently, functional explanations have usually focused on ways in which play during early development could benefit animals as adults. Hypothesized functions of play have included motor training, and social and cognitive development. However, examination of these hypotheses through play deprivation (Müller-Schwartze 1968; Caro 1980), natural suppression of play under harsh environmental conditions (Baldwin and Baldwin 1974, 1976; Bekoff 1976; Sommer and Mendoza-Granados 1995), or correlations between results of play fights and later dominance (Adams and Boice 1989; Araba and Crowell-Davis 1994) has revealed surprisingly little evidence for long-term effects of play; therefore, attention has also been paid to more immediate benefits of play in young animals. For example, play may provide opportunities for self-assessment (Thompson 1996, 1998), learning routes through the natal area (Stamps 1995), gaining dominance (Pellegrini and Smith 1998), modulating juvenile aggression (Drea et al. 1996), mastering immediate foodrelated or spatial cognition skills (Chalmers and Locke-Haydon 1984; Bjorklund and Brown 1998), or achieving heat/energy dispersal (Barber 1991). We briefly outline the four most clearly delimited and frequently promoted general hypotheses about play (Bekoff and Byers 1998; Burghardt 1998b).

A simple explanation for the apparent unity of mammalian play is that play is a side effect of other specific features of mammalian life history and physiology. According to the "surplus resource model" (Burghardt 1988, 1999) and its modification by Coppinger and Smith (1989), young mammals, in contrast to rep- 
tiles, can afford to play because they possess an aerobic metabolism that enables prolonged vigorous activity, and because they receive parental care, which includes the provisioning of milk and a degree of protection from predators. Play, according to this model, is a way in which juvenile mammalian behavior is remodeled into adult behavior; this "metamorphic" character of play explains its variability. The surplus resource model is not an hypothesis about the adaptive value of play. On the contrary, it proposes that the primary processes that lead to the phylogenetic appearance of play are merely side effects of other typically mammalian adaptations. Adaptive modifications of play evolved later and contributed to the diversification of play in various taxa. Hence, this hypothesis does not propose a general function of play, but rather delineates the aggregate of proximate, phylogenetic, and ontogenetic factors that make up the singularity of play.

The "surplus energy hypothesis," as originally put forth by Friedrich Schiller and later by Herbert Spencer (1898), noted that "higher animals" obtain better nutrition than "inferior species" during early ontogeny, and therefore have to let off the excess energy in play. Barber (1991) made the hypothesis more specific by arguing that young mammals are often not limited in energy. They benefit from play because the vigorous, 3-dimensional movements and the associated emotional arousal activate the sympathetic nervous system. Resultant acute and chronic increases in metabolic rate, and especially in brown adipose tissue thermogenesis, may produce a defense against cold and obesity, and enhance resistance to pathogens. According to the surplus energy hypothesis, play provides immediate benefits that are not directly related to the specific form of play.

Perhaps the most intuitive and widely accepted theory about the benefits of play is the practice theory of Groos (1898). According to this theory, play in early ontogeny prepares the animal for later life by perfecting critical behavioral patterns. Among numerous offshoots of this theory, the motor training hypothesis of Byers is the best developed. Originally, Byers (1984) suggested that the ancestral form of play was locomotory play and its function was motor training to avoid predators. During fur- ther evolution, play was modified, specialized, and diversified in different taxa according to selective pressures acting on the respective populations. For instance, in highly gregarious and polygynous large-bodied ungulates, social play evolved which closely mimics agonistic competition, especially among males. Later, Byers and Walker (1995) refined the hypothesis. They argued that performancedependent muscle fiber differentiation and cerebellar synaptogenesis are the probable long-term effects of the specific movements performed during play. Byers (1998) labels this proposal the "sensitive period hypothesis." The sensitive period hypothesis propounds very specific and permanent (neuro)physiological effects of play which lead to enhanced skill, an optimal speed/force ratio, and greater economy of important species-typical movement patterns.

Thompson (1998:192) recently suggested another general function of play, namely that it provides developing individuals with immediate feedback on their physical abilities; in other words, play is an efficient method for "self-assessment." According to this hypothesis, young animals test themselves by repeatedly performing a challenging locomotor or social action, or object manipulation. If they repeatedly succeed in performing a task, they switch to a more challenging task; if they fail, they may switch to an easier task. The self-assessment hypothesis suggests that benefits of play are immediate and mostly in the cognitive domain.

In Table 1, we have attempted to identify how the predictions derived from our hypothesis differ from those of the four alternate hypotheses. To do this we first considered predictions listed explicitly by Burghardt (1988) and Barber (1991), and some predictions suggested by Byers (1998) and Thompson (1998). Next we considered predictions which, according to our judgement, are clearly implied by the hypothesis in question. For each of our predictions, we decided whether each of the other four hypotheses leads to: (a) an identical or similar prediction (Agreement), (b) a different but not opposite prediction (Alternative), (c) an opposite prediction (Contrast), or $(d)$ no prediction.

In the next section, we examine our new 


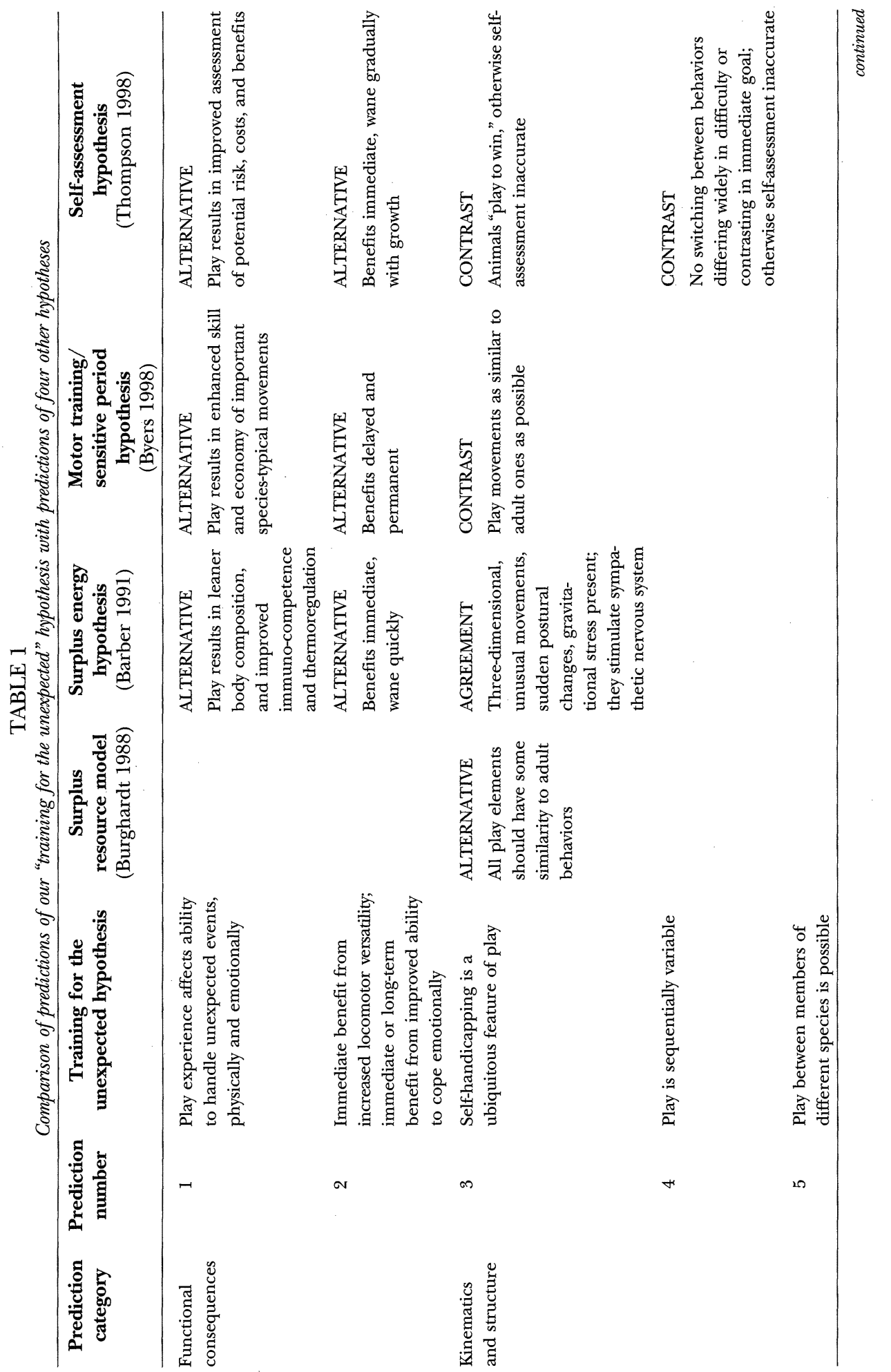




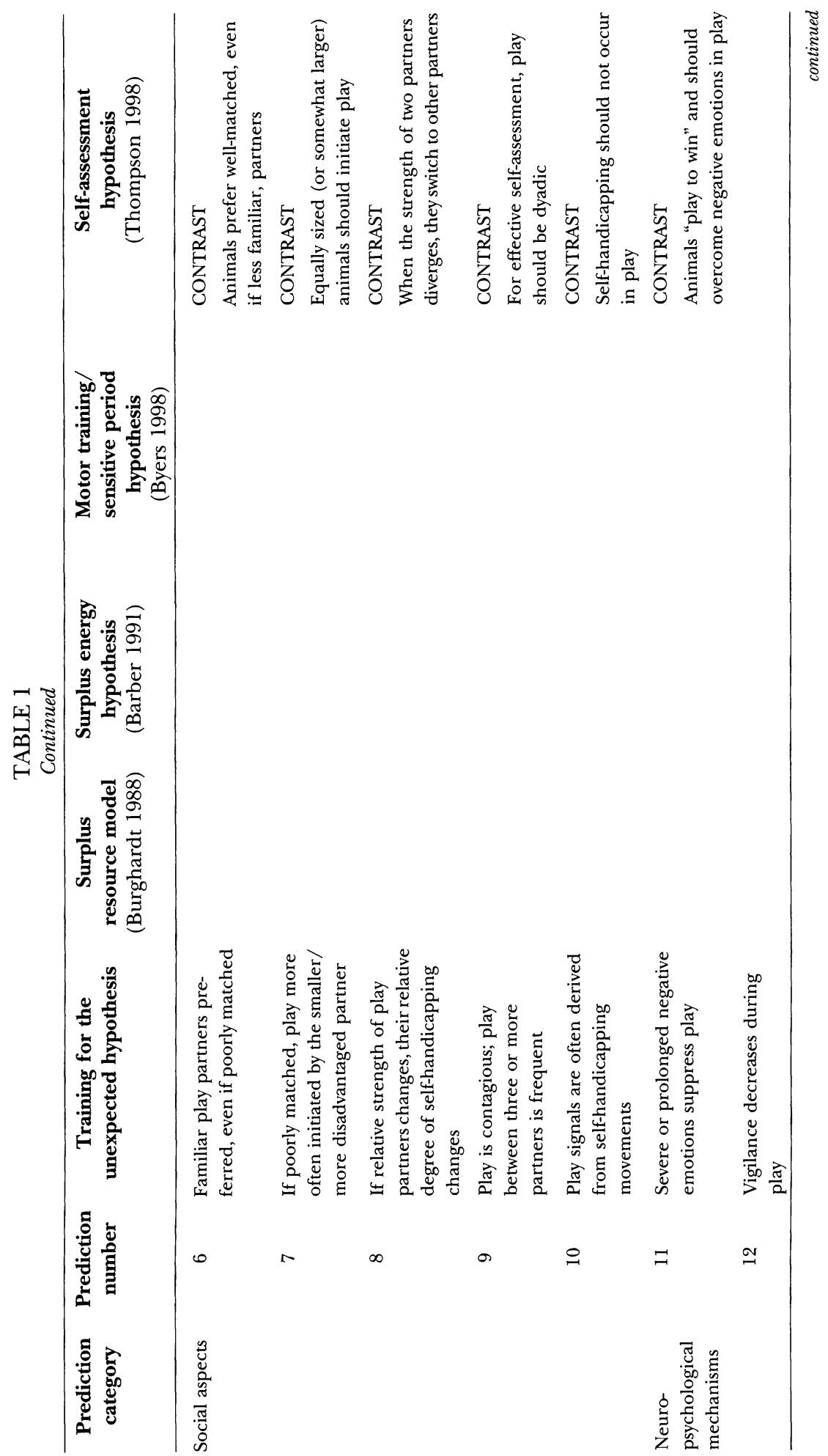




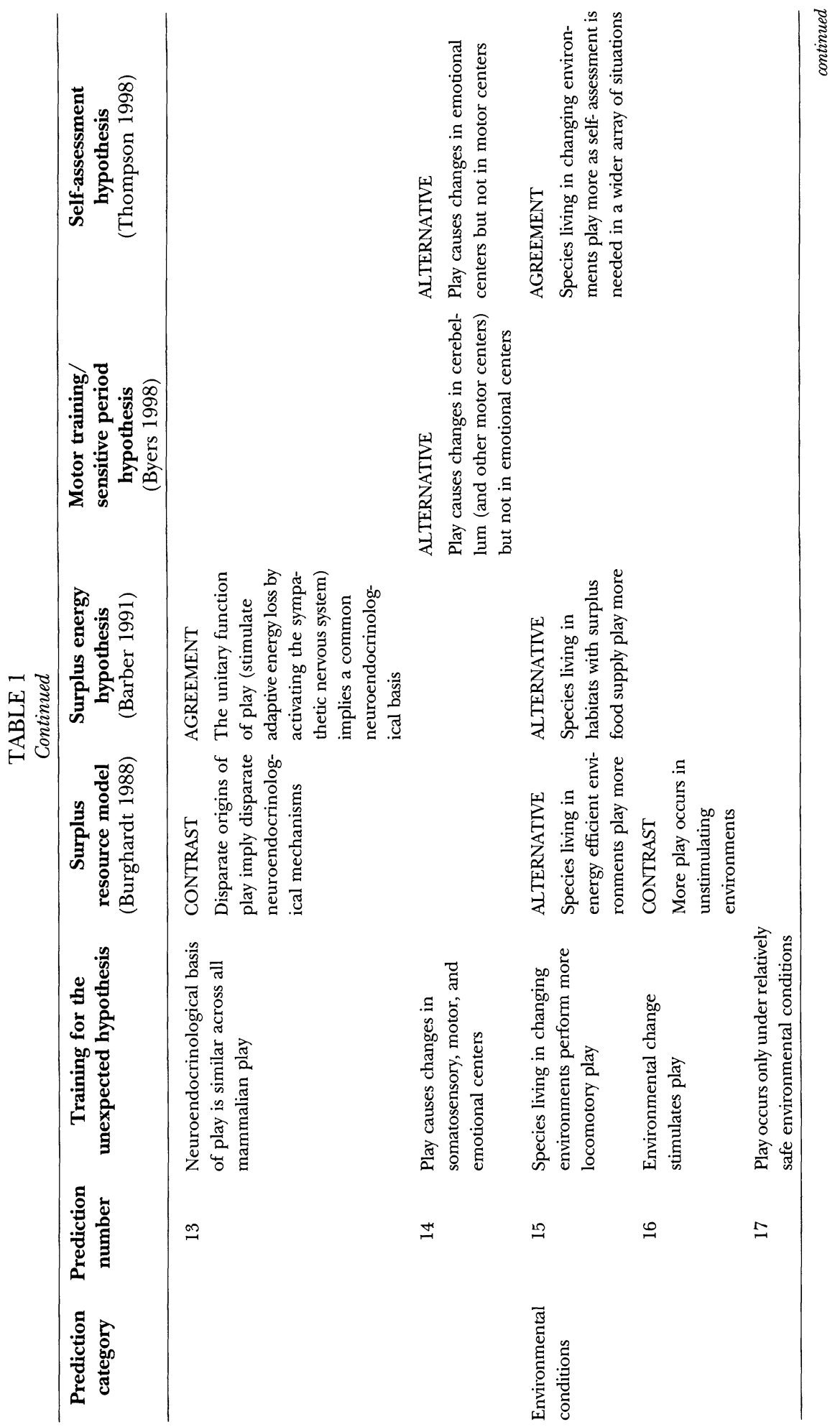




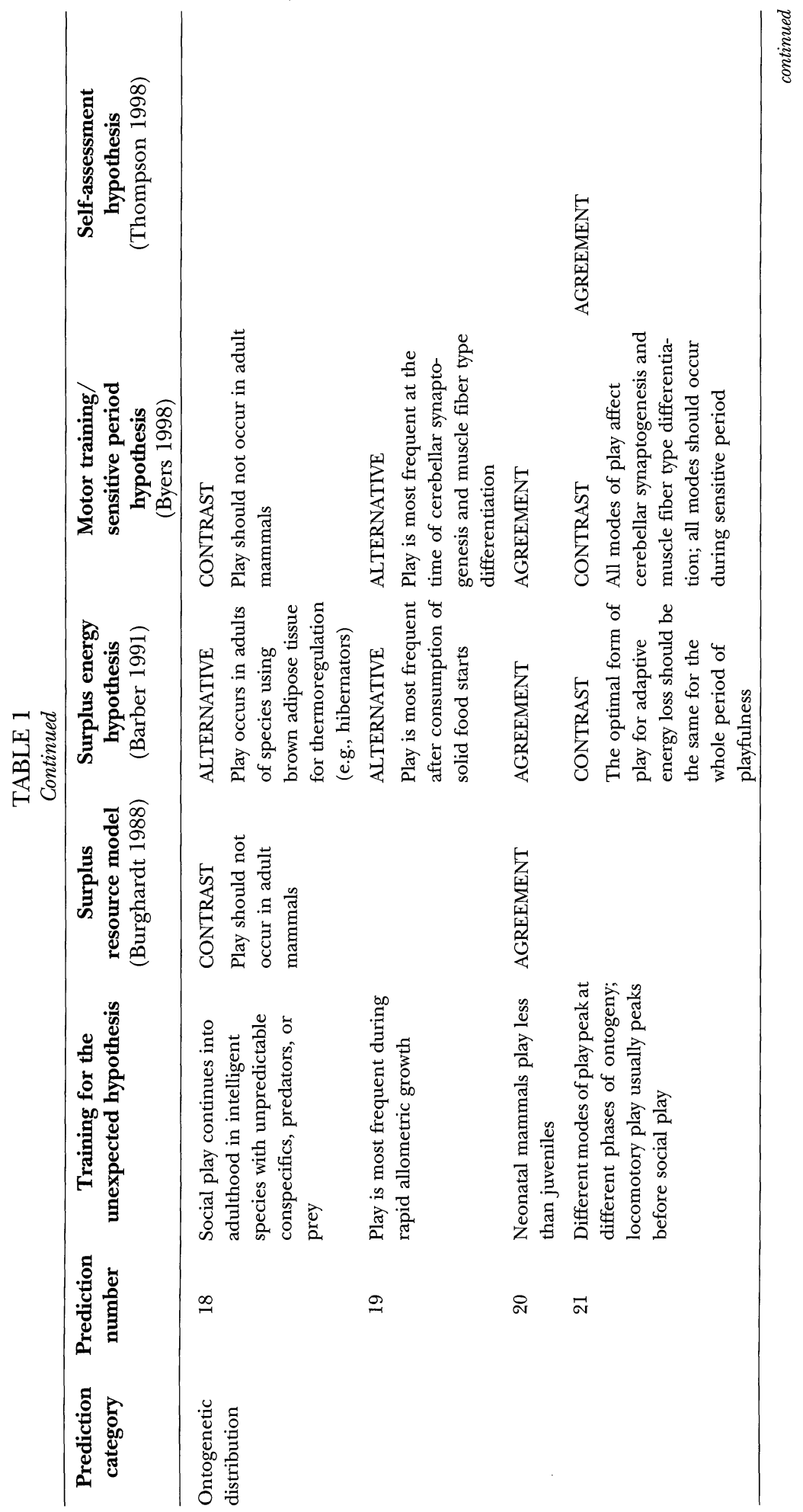




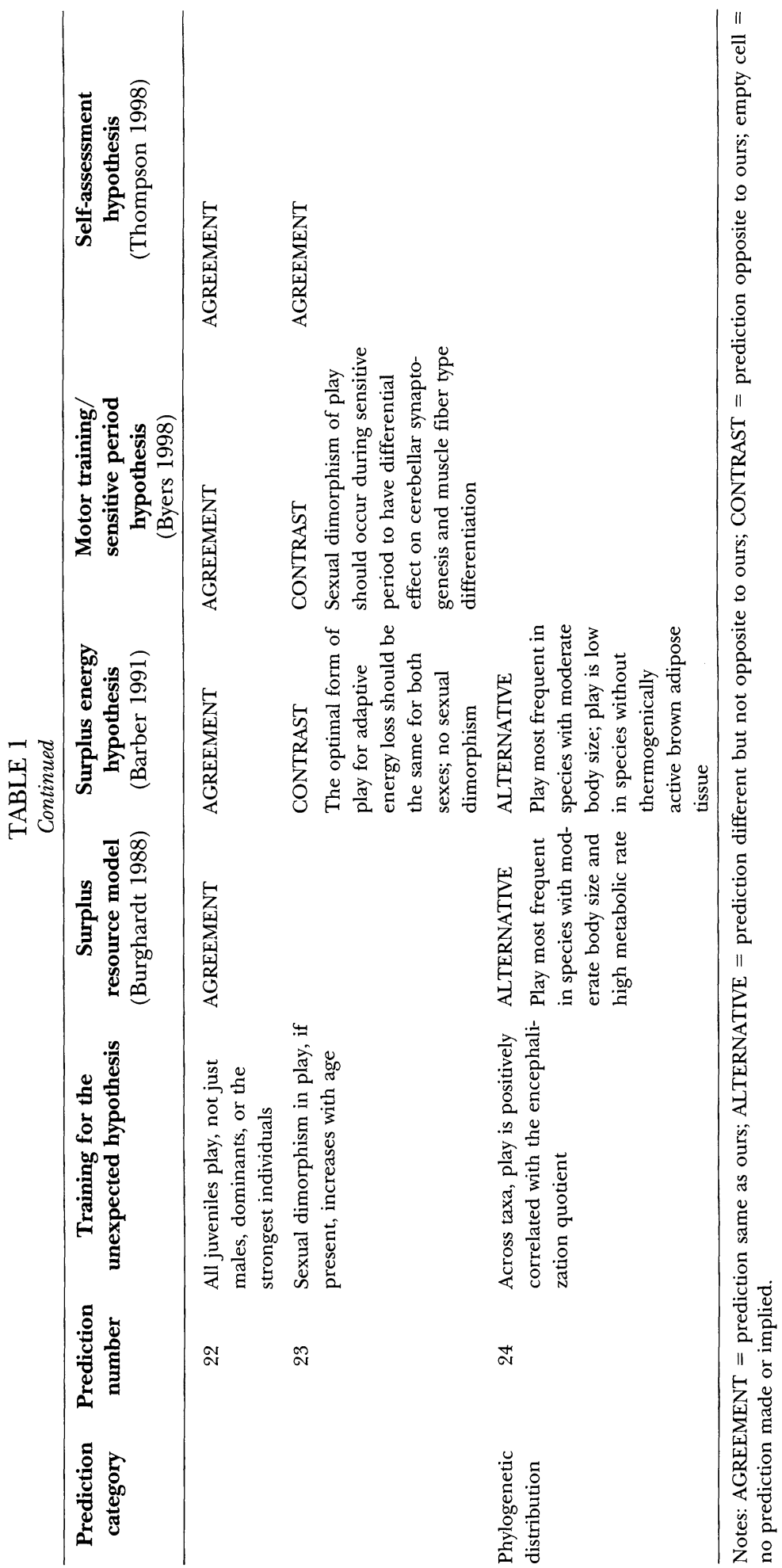


play hypothesis against the above four hypotheses. We discuss the existing empirical support for our predictions, and suggest future research needed to investigate the validity of each hypothesis.

\section{SuPPort For The "Training For The UneXPeCTED” HyPothesis And Its Alternatives}

FUNCTIONAL CONSEQUENCES OF PLAY

In this section, we refer to correlational studies that have investigated within-species natural variation in play and laboratory studies that have examined the effects of play directly through experimental manipulation of the amount of play. There is some correlational support for Prediction 1 of the "training for the unexpected" hypothesis in human studies. Pellegrini (1995) found that the ability of young boys to switch activities during roughand-tumble play is correlated with their later scores on a test of social problem-solving ability. Thus, experience gained from switching between activities in play may be associated with greater behavioral plasticity in unexpected or novel circumstances. Similarly, Saunders et al. (1999) found a correlation between playfulness and coping skills in preschoolers.

To our knowledge, our prediction that play experience increases movement flexibility when recovering from awkward positions has not been tested. On the other hand, there are experimental data that support our prediction that the ability to cope emotionally with challenging situations is compromised by play deprivation in the juvenile period. Most of these data stem from laboratory rats (Rattus norvegicus) deprived of social play via isolation during the fourth and fifth week of life and tested later (between 85 and 120 days of age) in a variety of social and nonsocial challenge tests. Potegal and Einon (1989) showed that these rats were more prone to attack and injure another rat after receiving an electric shock from the floor grid. This result can be interpreted as showing that social play deprivation produced a stronger reaction to an unexpected and unidentifiable aversive situation. Van den Berg et al. (1999a) found that rats previously isolated as juveniles unduly escalated conflicts when confronted with a resident rat in their territory, and had higher plasma corticosterone and epinephrine concentrations, compared with nonisolated controls. Rats isolated as juveniles also had a reduced motivation for social contact with an alien rat during the first 10 minutes after being placed in a neutral arena, although this trend tended to reverse in the second $10 \mathrm{~min}$ utes (Hol et al. 1999). In other studies, rats isolated as juveniles have displayed behavioral hyperactivity in open novel environments (Gentsch et al. 1988), slower habituation rates in an open field (Einon et al. 1978), and greater avoidance of open spaces in a preference test (da Silva et al. 1996).

The disadvantage of these studies is that isolation deprives the juvenile not only of play but also of other forms of contact and sensory stimulation from companions. However, the finding that the daily provision of a drugged (nonplayful) partner during the isolation period did not prevent the effects of isolation, whereas providing a normal play partner did prevent these effects (Einon et al. 1978; Potegal and Einon 1989), suggests that the consequences of social isolation may indeed be due largely to play deprivation. As a whole, these results suggest that play deprivation results in increased fear and uncertainty in novel environments, and more escalated aggressive behavior towards conspecifics in serious conflicts, as predicted from our functional hypothesis.

By contrast, there is little direct evidence for the adaptive effects of play predicted by Barber's surplus energy hypothesis. The prevention of obesity through heat production does not seem plausible, given that energy expenditure in play is generally low. Even playful young kittens (Felis catus) allocate only $4 \%$ of their energy expenditure to play (Martin 1984). Furthermore, there are examples of intense play in situations when the prevention of obesity was not an adaptive goal. Kittens whose milk supply was experimentally limited showed more play than normal (Martin and Bateson 1985), and young harbor seals (Phoca vitulina) were observed to play most at the time of fat accumulation (Renouf 1993).

The motor training/sensitive period hypothesis in its strong form (play during a sensitive period is necessary for normal behavioral development) is rebutted by the fact that, de- 
spite suppression of play due to very harsh natural conditions or laboratory manipulation, animals display qualitatively normal prey-catching and social behavior (Baldwin and Baldwin 1974, 1976; Bekoff 1976; Caro 1988; Sommer and Mendoza-Granados 1995). Even in its less strong form (play experience during a sensitive period affects the form and efficiency of species-typical movements), there is contradictory evidence. Caro (1980) found that the stimulation of extra object play in kittens through provision of suitable objects did not alter subsequent predatory behavior. Play deprivation in rat isolation studies has generally resulted in differences in the quantity, rather than quality, of adult social behavior. For example, prior isolation of rats increased the latency and decreased the frequency of social behavior elements, but did not alter their basic form and sequential patterning (van den Berg et al. 1999b). Given the similarity of certain play movements and elements of sexual behavior in male rats (Pellis 1993), adult male sexual behavior motor patterns should be affected by juvenile play deprivation, according to the motor training/sensitive period hypothesis. However, van den Berg et al. (1999a) found that the capacity to perform sexual motor acts was intact in rats isolated as juveniles. Also, their intromission/mount ratio, which is reduced in exhausted or inexperienced male rats, was unaffected; thus their copulating skill was comparable to controls.

Thompson's (1998) self-assessment hypothesis predicts that reduced play experience results in an impaired ability to assess risk, costs, and benefits. The effects of social isolation on emotional coping ability in rats are compatible with this prediction as well as our own.

In regard to the timing of beneficial effects of play (Prediction 2), Byers (1998) argued that play has nonnegligible energy and survival costs for juveniles, but no benefits for juvenile survival have been documented; therefore the adaptive benefits of play must occur later in life. However, studies that investigate the impact of play experience on short and long-term rates of mortality from different causes are lacking. As to the permanency of play effects, rodent play deprivation studies show that many effects on behavior can be reversed or alleviated by later social experience
(Gentsch et al. 1988; Potegal and Einon 1989). These results suggest that, contrary to the motor training/sensitive period hypothesis, the behavioral effects of play deprivation are not (solely) mediated by permanent effects on cerebellar synaptogenesis and muscle fiber differentiation.

\section{KINEMATICS AND STRUCTURE OF PLAY}

The ubiquitous presence of self-handicapping positions and movements in play sequences is the major prediction of our hypothesis about the form of play behavior (Prediction 3). Self-handicapping elements need not resemble any "serious" adult or juvenile motor pattern, as they can mimic movements that occur without an animal's active contribution. On the contrary, the motor training/sensitive period hypothesis implies that play movements are similar to "serious" adult movements because optimal permanent tuning of muscle types and cerebellar synapses can only be achieved if the "right" movements are performed during the sensitive period. The selfassessment hypothesis is also at variance with the occurrence of self-handicapping movements because animals should "play to win" (Thompson 1998:197); that is, they should try to achieve success in a play bout with maximal effort because, otherwise, their self-assessment will be inaccurate. According to the surplus resource model, "imperfect" elements are possible in play. They should still bear some resemblance to adult "serious" behavior elements, however, because play is, according to that model, a behavioral bridge between the periods of juvenile dependence and adult responsibilities (Burghardt 1988:130).

In support of our hypothesis, there is ample evidence that self-handicapping-in the sense that animals deliberately do not exert full control over their movements or actively put themselves into disadvantageous positions-is omnipresent in play. First, a prominent feature of play behavior elements is that they are exaggerated (Bekoff and Byers 1981; Fagen 1981; Burghardt 1984). Playful running and approaches have been described as "bouncy" in domestic dogs (Canis familiaris), wild canids, and piglets (Sus scrofa) (Bekoff 1974; Biben 1983; Newberry et al. 1988); playful social interactions as "capriciously exaggerated" in 
chimpanzees (Pan troglodytes) (Spijkerman et al. 1996); hops as "frisky" in punarés (Thrichomys apereoides) (Wilson and Kleiman 1974; Thompson 1998) and "frantic" in rats (Panksepp 1998); torso movements as "jerky" in bighorn sheep (Ovis canadensis) (Berger 1980); manipulation of objects as "boisterous" in cats (Felis catus) (Hall 1998); and water play as "ebullient" in harbor seals (Phoca vitulina) (Renouf 1993). These adjectives are shortcuts for saying that the play elements are too disproportional, too distorted, too fast, too uncontrolled, or too quickly repeated in comparison with their "serious" counterparts and, hence, are less suited to achieving the apparent proximate goal of those movements, such as escape, effective object handling, or overpowering an opponent.

Second, vigorous rotational elements are among the most frequent elements in play and are prominently featured in the play descriptions of many species. These movements include head shakes, tosses and jerks, neck and torso twists, heel kicking with lateral rotation, high speed turns, somersaults, and pirouettes (Müller-Schwartze 1968; Gentry 1974; Wilson and Kleiman 1974; Byers 1977; Fagen and George 1977; Berger 1980; Biben 1983; Pellis and Pellis 1983; Byers 1984; Rasa 1984; Gomendio 1988; Rothstein and Griswold 1991; Renouf 1993; Miller and Byers 1998; Byers 1999). In a systematic study, Byers (1984) observed head shakes, head jerks, or neck twists in the play of all 12 ungulate families investigated; they were the second most widely occurring type of behavior found in play after running. Most rotatory actions involve highspeed angular movement of the head and, hence, impair sensory and spatial orientation.

Third, play movements have more degrees of freedom than other types of behavior (Golani 1992; Fontaine 1994). For instance, mammals usually do not use rotation in the frontal plane in their "serious" behavior but often add this degree of freedom to their movements in play. Primates use head tilts to communicate playful motivation (Sade 1973), and ungulates often kick their heels to one side during locomotory play. Baldwin and Baldwin (1974) reported that squirrel monkeys (Saimiri sciureus) signal play intent by looking between their legs. We may speak about deliberate kine- matic plasticity in play that mimics the "enforced kinematic plasticity" that might be inflicted by an external force. These positions are self-handicapping because the animal sees the environment from unusual angles and is placed in bilaterally asymmetric positions that limit kinematic options in the next move.

Fourth, animals in play often perform object manipulation or social interactions in disadvantageous positions. Different species of primates exhibit play behavior while hanging by their hands, feet, or tails (Baldwin and Baldwin 1974; Aldis 1975), or they replace the usual quadrupedal walking with unstable bipedal locomotion during play (Fontaine 1994). Young animals of many predatory mammalian species exhibit play behaviors (socially or with objects) while lying on their side on the ground (Fagen 1981).

Fifth, use of self-handicapping actions by larger or stronger animals that engage weaker partners in play has been reported in, for example, five species of macropodoids (Macropus parryi, M. robustus, $M$. rufogriseus, $M$. rufus, Thylogale billardierii) (Watson and Croft 1996; Watson 1998), African elephants (Loxodonta africana) (Moss 1988:163), coyotes (Canis latrans) (Bekoff, unpublished observations), squirrel monkeys (S. sciureus) (Biben 1989), hamadryas baboons (Papio hamadryas) (Pereira and Preisser 1998), and chimpanzees ( $P$. troglodytes) (Mendoza-Granados and Sommer 1995).

Our second structural prediction is that play is sequentially variable (Prediction 4). High sequential variability of play has been documented in several species. Bekoff and Byers (1981) reported that sequences of play in infant canids were significantly more variable than sequences of agonistic behavior. Newberry et al. (1988), observing piglets ( S. scrofa) in a seminatural enclosure, identified six play markers (elements occurring only in play) and found that all 22 remaining behavioral elements in the ethogram occurred at least once just before or just after one or more of the play markers. Rasa (1984) observed that dwarf mongooses (Helogale undulata) switch very frequently between behavior representative of prey capture, social interaction, enemy avoidance, and exploration during play, and Gentry (1974) reported similar variability in 
the play of Stellar sea lions (Eumetopias jubatus). Where locomotory, social, and object play occur in the repertoire of a species, the relative frequencies of these different modes of play may change during ontogeny (Newberry et al. 1988), during the course of a day (Byers 1977), or even within a play session (Müller-Schwartze 1968; Rasa 1984). Nevertheless, elements of these three modes of play (or at least those of locomotory and social play) are often intermixed within a single bout of play (Inhelder 1955; Müller-Schwartze 1968; Gentry 1974; Aldis 1975; Biben 1983; Pellis and Pellis 1983; Newberry et al. 1988; Pedersen et al. 1990; Mendoza-Granados and Sommer 1995; Vanderschuren et al. 1997; Thompson 1998).

Interestingly, the presence of self-handicapping elements in play is implied by the most widely used definition of play: "play is all motor activity that appears purposeless" (Bekoff and Byers 1981; Bekoff 1984; Pellegrini and Smith 1998; Byers 1999). This definition is intuitively appealing despite the inclusion of a subjective judgment. Play does appear purposeless, but not because it has no function. The "purposelessness" of play is striking because some movements are inconsistent with the apparent purpose of the behavior that immediately precedes or follows the playful behavioral elements. For example, if playful running by piglets is viewed as training for escape from danger, it seems pointless to perform a deliberate flop-over after a few meters of scampering. However, this behavior does make sense if the animals are preparing themselves for the possibility of a fall while making a rapid directional change during flight.

\section{SOCIAL ASPECTS OF PLAY}

Of the evaluated hypotheses, three (those of Burghardt, Barber, and Byers) do not give specific predictions about the choice of partners in play or related social aspects. The selfassessment and "training for the unexpected" hypotheses do offer predictions about social play, but these predictions are opposing. According to our hypothesis, familiarity is an important criterion for choice of play partners (Prediction 6), whereas the self-assessment hypothesis suggests that playmates are selected strictly according to their physical match. In polycotous species, young often prefer siblings as playmates (Dobao et al. 1985; Holmes 1994). Several studies also document the tendency of young mammals to play preferentially with youngsters of their age (e.g., Berger 1980; Byers 1980; Rothstein and Griswold 1991; Mendoza-Granados and Sommer 1995; Thompson 1996). However, it is often unclear whether this preference is due to familiarity or a match in body size.

Studies that explicitly identify the role of relatedness/familiarity versus body size match give conflicting results. For example, in sable antelope (Hippotragus niger), related individuals were not preferred if they were not matched in size (Thompson 1996), whereas in bighorn sheep (Ovis canadensis) and chimpanzees ( $P$. troglodytes), familiarity affected the choice of playmates more than age (Berger 1980; Markus and Croft 1995). Differences between studies may be related to the degree of difference in body size, age, and familiarity between available play partners, and methodological differences in quantifying choice of play partners. More long-term studies are needed to identify the prevalent pattern over an array of species. Such observations should also demonstrate what happens when the strength of two previously matched partners diversifies. According to the self-assessment hypothesis, the animals will switch their preference to bettermatched partners, whereas we predict that they will continue to play with each other and use self-handicapping to compensate for the difference (Prediction 8).

The "training for the unexpected" and selfassessment hypotheses give two additional contrasting predictions about social aspects of play. Regarding play initiation (Prediction 7), the available evidence tends to support the self-assessment hypothesis in that the larger partner more often initiates play or there is no effect of body size (Owens 1975; Pellis and Pellis 1991; Mendoza-Granados and Sommer 1995; Biben 1998; Thompson 1998). In some species, however, younger animals are more often the initiators (Gomendio 1988) or weaker individuals initiate more escalated forms of contact play (Watson 1998). Regarding the contagious nature of play (Prediction 9), social play often involves more than two animals (Gentry 1974; Pedersen et al. 1990; 
Loranca et al. 1999), supporting our prediction over Thompson's prediction that play should be dyadic. In domestic piglets, triadic play amounted to about $20 \%$ of all interactions (M Špinka, unpublished observations).

Our prediction that play signals are often derived from self-handicapping behavior (Prediction 10) is supported by many examples. Self-handicapping postures, such as lying on side or looking between the legs, and movements such as play bows, roll-overs, pivots, and head tosses, are used especially often immediately before vigorous locomotory and social play actions (Geist 1963; Müller-Schwartze 1968; Baldwin and Baldwin 1974; Wilson and Kleiman 1974; Pellis and Pellis 1983; Gomendio 1988; Newberry et al. 1988; Rothstein and Griswold 1991; Bekoff 1995; Watson and Croft 1996; Miller and Byers 1998); thus they have a specific metacommunicative function (Bekoff $1975,1995)$. They affect the behavior of the receiving animal in such a way that the sender is able to sustain the playful interaction despite the vigorous action that follows.

There is a dramatic difference between the movements and postures used to signal intent to attack and those used to signal intent to play. Threatening animals display their broad side, use frontally symmetric positions, and perform symmetrical movements. Given that body size and symmetry are reliable indicators of physical fitness (Møller 1998), these displays express signaler condition. In contrast, the self-handicapping movements and postures used to signal playful intent have elements similar to those used by weak, tired, subordinate, or even sick, injured, or developmentally handicapped animals-lowering down, decreasing apparent body size, gaping, shaking the head, and twisting asymmetrically. Compare the standing-tall threat stance of dogs ( $C$. familiaris) with the "play bow" signal in which the front part of the body is lowered (Bekoff 1977).

\section{NEUROPSYCHOLOGICAL MECHANISMS INVOLVED IN PLAY}

We predict that play is strongly suppressed by negative emotional states (Prediction 11), whereas the self-assessment hypothesis predicts that animals should "play to win," implying that they should be prepared to overcome negative emotions in play. Although it is a conventional wisdom that sick, injured, frightened, frustrated, depressed, or angry animals do not play, little direct evidence is available. Quantitative studies could be used to assess whether animals are willing to expend more time or energy for an opportunity to play in relation to their level of well-being (e.g., through demand curve methodology; Dawkins 1990).

The "training for the unexpected" hypothesis predicts that there is a specific neuroendocrinological basis of play that is similar across different play modes and across various mammalian species (Prediction 13). On the contrary, Burghardt's surplus resource model, with its claim about disparate origin and lack of a general function for play, implies that different neuroendocrinological substrates and processes underlie different play patterns. Thus far, the evidence collected on laboratory rats suggests that play may specifically tap brain mechanisms involved in somatosensory perception, emotional experience, and arousal control.

First, there is evidence that regions of brain that process certain types of somatosensory information are particularly relevant for normal play to occur (Siviy 1998:233-234). Cells in the parafascicular nucleus of the thalamus (PF), having large receptive fields and high thresholds for excitation, receive somatosensory information of a very diffuse nature, whereas cells in the ventrobasal thalamic complex (VTC), having small receptive fields and low thresholds, receive somatosensory information of a very detailed nature. Lesions to the PF substantially reduce "pinning," an element used in quantifying rat social play, while having minimal effects on other behavior. By contrast, lesions to the VTC have a minimal effect on play. PF activity also increases substantially during play episodes, as measured by the c-fos technique. Interestingly, Panksepp (1998:288) reports that full body tickling was more effective in inducing $50 \mathrm{kHz}$ chirping vocalizations in rats (presumably connected to play mood) than tickling of individual parts of the rat body. Taken together, these findings suggest that nonspecific reticular nuclei involved in the perception of high-intensity whole-body sensations, like those in the PF, specifically mediate play urges. This is in agreement with 
our hypothesis that play trains animals for coping with unexpected movements and positions rather than perfecting specific skilled movements.

Second, in the reward domain, opioids appear to be involved in play in a specific way. For instance, low doses of morphine increase play and opiate antagonists reduce it, although the same manipulations have opposite effects on the desire for general social interaction (Panksepp 1998:293). Ligands of $\mu$-opioid receptors influence social behavior elements that occur in play but not those unrelated to play (Vanderschuren et al. 1995b). Also, neonatal cocaine exposure affects subsequent learning based on a play reward in a different way than learning based on a food reward (Willford et al. 1999).

Third, play is dependent on monoaminergic systems in a distinct way (reviewed by Siviy 1998). In the anticipatory and warm-up phases of a play bout, the ventrotegmental dopaminergic system is involved. Once a play bout is in full stride, high noradrenergic activity enhances play. On the other hand, serotonergic activity must be low for play to occur.

Thus, for rats, evidence is accumulating that play might, indeed, employ the brain in a specific way. However, we do not know yet whether similar mechanisms are active during play in other mammals because almost no studies focused on brain mechanisms underlying play have been conducted in other species.

The "training for the unexpected" hypothesis predicts that play activity results in measurable changes in somatosensory, motor, and emotional brain centers (Prediction 14). The motor training/sensitive period hypothesis implies that changes should be in motor control areas, especially in the cerebellum, rather than in emotional centers. The opposite prediction follows from the self-assessment hypothesis. Depriving young rats of social play through isolation during the age when play is most frequent resulted in long-term changes in $\mu$-opioid receptors in basolateral amygdala and bed nucleus of stria terminals, and in к-opioid receptors in several cortical areas (van den Berg et al. 1999c). Rats reared in isolation also have permanently altered levels of dopamine, norepinephrine, and serotonin (reviewed by Siviy 1998:235). These monoamines are important for coordinating an organism's response to stress. Thus, it appears that juvenile play does alter the neurochemistry of brain emotional centers. More evidence is needed, however, that should include species other than the rat and should more precisely distinguish whether the effects are specifically due to play deprivation or some more general aspects of the social isolation procedure. Although the specific effects of play on motor centers have not been tested, it is known that in cerebellar Purkinje cell axons, the selection of which synapses will be retained is experience dependent and occurs at about the age when rats play most (Byers 1998). In sum, the limited available evidence suggests that somatosensory, emotional, and motor centers of the brain are affected by play experience.

\section{ENVIRONMENTAL GONDITIONS FOR PLAY}

The "training for the unexpected" hypothesis predicts more locomotory play in species that live in very variable or changing environments (Prediction 15). The surplus resource model suggests that animals living in more energy efficient environments should play more. The surplus energy hypothesis predicts more play in species that live in habitats with surplus food. Examples can be found of species that fit each of these predictions. Thus, bighorn sheep (O. canadensis) living in variable hilly terrain, harbor seals ( $P$. vitulina) living in an energy-efficient water environment, and Hanuman langurs (Presbytis entellus) living in a food-rich habitat are all highly playful (Berger 1980; Renouf 1993; Sommer and MendozaGranados 1995). Systematic studies across numerous, taxonomically closely related species living in different habitats are needed to determine which of these predictions holds true.

Our hypothesis predicts that a change in habitat or in a significant environmental feature should stimulate play (Prediction 16). On the contrary, Burghardt's surplus resource model predicts more play in an unstimulating environment. There is evidence that animals tend to play in new, rare, or more demanding local habitats. The stimulatory effect of fresh snow or shallow water on play in dogs and humans is well known. Berger (1980) found that bighorn sheep (O. canadensis) living in British Columbia's Chilcotin hills spent about one 
fourth of their total play time in small sand bowls at the base of the hills. Byers (1977) reported that Siberian ibex kids (Capra siberica) preferred to play on sloped rather than flat ground. De Waal (1996:47) described rhesus monkeys (Macaca mulatta) as being very preoccupied by a giant vertical wheel that they could spin rapidly, release, and thus catapult themselves meters high. It is well known that captive animals can be induced to play by the introduction of fresh bedding into their accommodation or by moving them temporarily into an alternative environment (e.g., Pedersen et al. 1990; Wood-Gush and Vestergaard 1991; de Passillé et al. 1995; Jensen et al. 1998). Mildly dangerous prey, sudden noise, or windy weather can stimulate play as well (MüllerSchwartze 1968; Biben 1979; Prescott 1985; Newberry et al. 1988).

Only our hypothesis makes a specific prediction in regards to the safety of the play environment (Prediction 17). Interestingly, if laboratory rats are kept in dim light (which is natural for them), exposure to intense light suppresses play but not other social behaviors (Vanderschuren et al. 1995a; Knutson et al. 1998). This makes sense when viewed from an evolutionary perspective, given that play activity by wild rats during periods of high visibility would probably increase their risk of predation. Our prediction that animals should play only when the environment is relatively safe ties in with our prediction that vigilance is reduced during play (Prediction 12), and with the observation of Biben et al. (1989) that squirrel monkey mothers ( $S$. sciureus) increased their level of vigilance when their offspring were at play.

\section{ONTOGENETIC DISTRIBUTION OF PLAY}

Thompson (1998:192, 200) hypothesized that the information gained through selfassessment in play facilitates normal development in differing environments, thereby implying that play should decline when animals reach adulthood. We predict, more specifically, that play should start at low levels in neonates, peak during the juvenile period, and decline later (Predictions 18 and 20). This prediction holds true for the vast majority of species examined (e.g., Biben 1983; Prescott 1985; Gomendio 1988; Newberry and WoodGush 1988; Renouf 1993; Byers 1998).
Burghardt's surplus resource model and Byers's sensitive period hypothesis imply that there should be no play (or very limited play) in adult mammals. Yet it is now well documented that adults of many species do play (Breuggeman 1978; Biben 1979; Berger 1980; Fagen 1981; Byers 1984; Rasa 1984; Zucker et al. 1986; Coppinger and Smith 1989; Enomoto 1990; Pedersen et al. 1990; Barber 1991; Pellis et al. 1993; Renouf 1993; Hall 1998; Miller and Byers 1998; Watson 1998). Barber's surplus energy hypothesis predicts adult play in species that use brown adipose tissue for thermoregulation, such as hibernators, but this prediction does not explain why play occurs in, for example, adult kangaroos, rats, primates, and pinnipeds, and why no adult play has been documented in hedgehogs (Erinaceus europaeus) (Fagen 1981). We expect to find adult play, especially in more intelligent species faced with the unpredictable behavior of conspecifics and, possibly, with relatively intelligent predators or prey. More data are needed to assess whether this is a robust mammalian trend.

Two of the alternative hypotheses differ from the "training for the unexpected" hypothesis in their predictions about when, during the juvenile period, play should occur. Where we predict that play will be most frequent during the period of rapid allometric growth (Prediction 19), Barber's surplus energy hypothesis predicts that play will peak when the consummation of solid food becomes prevalent. The sensitive period hypothesis of Byers predicts ontogenetic parallelism between play, on the one hand, and cerebellar synaptogenesis and muscle fiber differentiation on the other. This has been found in mice (Mus musculus), rats, and cats (F. catus) (Byers and Walker 1995). However, further analysis of the literature is needed to assess the level of support for the different predictions about the precise timing of the peak in play during the juvenile period.

We predict that different modes of play wax and wane at different ages within the same species (Prediction 21), whereas the surplus energy and sensitive period hypotheses imply an ontogenetically parallel course for all forms of play. Available evidence appears to favor the former prediction (Gentry 1974; Burghardt 
1998b). Our more specific prediction that locomotory play will precede social and sexual play during ontogeny also appears to be supported (Berger 1980; Berry and Signoret 1984; Prescott 1985; Gomendio 1988; Newberry and Wood-Gush 1988; Newberry et al. 1988; Haynes 1997). In spotted hyenas (Crocuta crocuta), by contrast, social play precedes locomotory play (Drea et al. 1996). This exception is in accord with our prediction that play has immediate benefits, given that withinden aggression among hyena siblings precedes locomotion outside the den. Similar developmental patterns are observed in coyotes (Canis latrans) and red foxes (Vulpes vulpes) (Bekoff 1974).

With respect to predictions about sex differences in play, Barber's surplus energy hypothesis predicts none; the optimal form for adaptive energy loss should be the same for both sexes. The sensitive period hypothesis implies that sexual dimorphism of play, where present, will occur throughout the sensitive period. We predict that the sexual dimorphism in play will increase with age (Prediction 23) because, presumably, the serious situations for which play provides training become increasingly disparate in the two sexes and because the benefits of play are partially immediate. Examples of pronounced, moderate, and nonexistent sex differences in play can be found in the literature (e.g., Byers 1977; Biben 1983; Prescott 1985; Caro 1988; Pedersen et al. 1990; Renouf 1993; Watson 1998). However, a majority of the available data supports the prediction of increasing sexual dimorphism in play with increasing age (Gentry 1974; Meaney et al. 1985; Newberry and Wood-Gush 1988; Newberry et al. 1988; Spijkerman et al. 1996; Haynes 1997; Smith et al. 1998). Available data also suggest that this difference is not dependent on concurrently diverging sex steroid levels (Meaney et al. 1985).

\section{PHYLOGENETIC DISTRIBUTION OF PLAY}

Where we predict more play in species with highly developed cognitive abilities and, hence, a high encephalization quotient (Prediction 24), Burghardt's surplus resource model predicts that moderately sized species with high metabolic rates should play the most. Barber's surplus energy hypothesis suggests that spe- cies with moderate body size and thermogenically active brown adipose tissue should be the most playful. In the only systematic study published so far, Byers (1999) found that play in Australian marsupials is associated with relative brain size but not with body size or metabolic rate; Ortega and Bekoff (1987) reported similar trends in birds.

\section{Directions For Future Research}

On the whole, our hypothesis appears to fare better than the four alternatives that we have evaluated. This assessment must be considered preliminary, however, because: (i) the evidence is fragmentary, (ii) there may be other relevant papers that we have not reviewed, and (iii) it was difficult to assess data from different sources using uniform criteria because of variations in methodology and emphasis. Consequently, further efforts are needed to elucidate which of the many predictions discussed above are generally supported across mammalian taxa.

The most direct evidence for any of the putative functional hypotheses of play could come from controlled experiments in which the amount of play experience is manipulated and the predicted effects on behavior, physiology, adult skill and/or coping, survival, and reproduction are recorded. The difficulty with these studies is that play deprivation usually removes other sources of stimulation as well, as, for example, when animals are socially isolated during the period when they would play the most. Thus, it is unclear whether the resulting effects are due specifically to the lack of play. More refined methods, such as the use of drugged play partners, employing short daily periods of play in isolates (Potegal and Einon 1989), or using a housing environment that inhibits play are promising, although typically restricted to species amenable to study in laboratory settings.

Exciting progress has been achieved in assessing the neurophysiological and neurochemical basis of play (Vanderschuren et al. 1997; van den Berg et al. 1999c), and promising investigations have been made into the emotional processes associated with play (Panksepp 1998). However, for a more complete understanding of the relationship between play behavior, the associated cognitive, emotional, 
and motivational processes, and the underlying brain machinery, considerable conceptual and experimental difficulties must be surmounted.

Given these difficulties, we suggest that substantial progress in understanding the function of mammalian play can be achieved by focusing on the ontogenetic, phylogenetic, and ecological distribution of play, and on sex differences in play. Widely scattered data can be drawn together, combined with available information on life-history strategies, and submitted to detailed analyses to verify quantitatively which of the trends predicted by the different hypotheses are supported within and across mammalian taxa.

\section{Final Remarks}

\section{THE "ONE FUNCTION-MANY FUNCTIONS" PROBLEM REVISITED}

While the core of our hypothesis is that play in mammals has one original function, namely to train for unexpected situations, clearly play behavior in its extant variety can fulfill various other functions in individual species and animals that differ in age and sex. To illustrate this "one ancestral-many derived functions" possibility, Byers (1984:44-45) compared the diversification of mammalian play to the evolution of the pentadactyl forelimb. Although the quantitative modifications of the mammalian manus are impressive (e.g., the prolongation of fingers in bats), the basic five-digit design is retained. Yet the ancestral function of walking has been complemented, or even replaced, by diverse new functions such as digging in anteaters and swimming in dolphins. Similarly, once play was established in mammalian behavioral design, it diversified in individual taxa to fulfill various specific functions.

A perhaps closer phylogenetic parallel can be drawn between mammalian play and mammalian rapid eye movement (REM) sleep, which is also omnipresent in mammals but absent in ectothermic vertebrates. Its modifications, including specializations such as unihemispheric sleep in dolphins (Tobler 1995), are impressive. Its amount and distribution vary substantially across mammalian taxa and it is correlated with such ecological variables as a safe sleeping place, life-history parameters such as precociality/altriciality, and niche types like herbivory/carnivory (Siegel 1995). Highly diverse functions for REM sleep have been proposed, including the maintenance of a high, stable brain temperature (Wehr 1992), ensuring recovery from sleep (Vertes 1986), memory and/or sensorimotor experience processing (Winson 1993; Ribeiro et al. 1999), compensation for brain processes that take place during non-REM sleep (Benington and Heller 1994), promoting brain development (Mirmiran 1995), and reinforcing psychological individuation (Jouvet 1998). Despite this diversity of forms and possible functions, REM sleep is considered a homologous trait that originated very early in mammalian history or even in reptilian ancestors of mammals (Siegel et al. 1998), probably to fulfill a substantial, although not yet fully elucidated, original function. In our view, there are strong indications that mammalian play may have a similar phylogenetic history.

Our hypothesis provides a plausible explanation about why play, specifically, could have diversified into such a rich array of forms with various derived functions. According to the constituents of play presented in this review, play should result in flexible reactions to unexpected situations. Play may thus result in more diverse behavior both within and between individuals. In other words, individuals may, through play, find and develop their own personal methods for coping with different kinds of unexpected misfortunes. Indeed, qualitative differences between individuals and between litters arise during juvenile play (Wilson and Kleiman 1974; Lund and Vestergaard 1998). Thus, play may increase phenotypic behavioral variability within populations, which, in turn, may open the door to the Baldwin Effect, a process by which novel variations become genetically fixed (Baldwin 1896; Parisi and Nolfi 1996). In this way, play may have acquired novel kinematic forms, causal links, developmental pathways, and beneficial functions in various lineages while still retaining its basic nature.

\section{A MULTIFACETED APPROACH TO PLAY:} THE PUZZLES OF PLAY

From our major hypothesis about the function of play, we have derived another four specific hypotheses: that self-handicapping is in- 
tegral to play, that play is stimulated by novelty and unpredictability, that play is associated with a specific emotional state, and that play presupposes high cognitive capacity. Our hypothesis about function (i.e., ultimate causation) is complemented by hypotheses about how this function is achieved (i.e., proximate causation in terms of both physical and mental processes involved in play), and why play is more predominant in some animals than in others (i.e., due to phylogenetic constraints).

Strictly speaking, none of the four derived hypotheses is a logical necessity for our core functional hypothesis to be true. On one hand, it may seem that presenting these hypotheses independently would be a more appropriate approach; on the other hand, function, proximate mechanisms, and phylogenetic constraints are intertwined in numerous ways, and knowledge of these interactions is essential for a full understanding of behavior (Curio 1994). This is especially true for play. Play is a robust behavioral phenomenon with several puzzling features, such as its kinematic and sequential structure, and ontogenetic and phylogenetic distribution. Any functional hypothesis about play must be comprehensive enough to encompass these features, and most previously published hypotheses about play have attempted to do so. For instance, Burghardt's surplus resource model attempts to incorporate physiological, life-history, and ecological conditions that support the evolution of play, and the sensitive period hypothesis of Byers about a neurodevelopmental mechanism is closely linked to the motor training functional hypothesis. This is why our proposal, although centered on function, is a complex theory about the nature of play. We hope that our new conceptual framework will lead to enhanced understanding of this fascinating behavior.

\section{REFERENCES}

Adams N, Boice R. 1989. Development of dominance in domestic rats in laboratory and seminatural environments. Behavioural Processes 19:127-142.

Aldis O. 1975. Play Fighting. New York: Academic Press.

Allen C, Bekoff M. 1997. Species of Mind: The Philosophy and Biology of Cognitive Ethology. Cambridge (MA): MIT Press.

Apanius V. 1998. Stress and immune defense. Pages 133-153 in Advances in the Study of Behavior, Volume 27: Stress and Behavior, edited by A P Møller, M Milinski, and P J B Slater. San Diego (CA): Academic Press.

Araba B D, Crowell-Davis S L. 1994. Dominance relationships and aggression of foals (Equus caballus). Applied Animal Behaviour Science 41:1-25.

Baldwin J D. 1986. Behavior in infancy: exploration and play. Pages 295-326 in Comparative Primate Biology, Volume 2, Part A: Behavior, Conservation, and Ethology, edited by G Mitchell and J Erwin. New York: Alan R. Liss.

Baldwin J D, Baldwin J I. 1974. Exploration and social play in squirrel monkeys (Saimiri). American Zoologist 14:303-315.

Baldwin J D, Baldwin J I. 1976. Effects of food ecology on social play: a laboratory simulation. Zeitschrift Für Tierpsychologie 40:1-14.

Baldwin J M. 1896. A new factor in evolution. American Naturalist 30:441-451, 536-553.

Barber N. 1991. Play and energy regulation in mammals. Quarterly Review of Biology 66:129-147.
Barrett L, Dunbar R I M, Dunbar P. 1992. Environmental influences on play behaviour in immature gelada baboons. Animal Behaviour 44:111-115.

Bekoff M. 1974. Social play and play-soliciting by infant canids. American Zoologist 14:323-340.

Bekoff M. 1975. The communication of play intention: are play signals functional? Semiotica 15: 231-239.

Bekoff M. 1976. Animal play: problems and perspectives. Pages 165-188 in Perspectives in Ethology, edited by P P G Bateson and P H Klopfer. New York: Plenum Publishing.

Bekoff M. 1977. Social communication in canids: evidence for the evolution of a stereotyped mammalian display. Science 197:1097-1099.

Bekoff M. 1984. Social play behavior. BioScience 34: 228-233.

Bekoff M. 1995. Play signals as punctuation: the structure of social play in canids. Behaviour 132: 419-429.

Bekoff M, Allen C. 1998. Intentional communication and social play: how and why animals negotiate and agree to play. Pages 97-114 in Animal Play: Evolutionary, Comparative and Ecological Perspectives, edited by M Bekoff and J A Byers. Cambridge: Cambridge University Press.

Bekoff M, Byers J A. 1981. A critical reanalysis of the ontogeny of mammalian social and locomotor play: an ethological hornet's nest. Pages 196-337 in Behavioral Development: The Bielefeld Interdisciplinary Project, edited by K Immelmann et al. Cambridge: Cambridge University Press. 
Bekoff M, Byers J A, editors. 1998. Animal Play: Evolutionary, Comparative and Ecological Perspectives. Cambridge: Cambridge University Press.

Benington J H, Heller H C. 1994. Does the function of REM sleep concern non-REM sleep or waking? Progress in Neurobiology 44:433-449.

Berger J. 1980. The ecology, structure and function of social play in Bighorn sheep (Ovis canadensis). Journal of Zoology 192:531-542.

Berry M, Signoret J-P. 1984. Sex play and behavioural sexualization in the pig. Reproduction, $\mathrm{Nu}$ trition, Development 24:507-513.

Biben M. 1979. Predation and predatory play behaviour of domestic cats. Animal Behaviour 27: 81-94.

Biben M. 1983. Comparative ontogeny of social behaviour in three South American canids, the maned wolf, crab-eating fox and bush dog: implications for sociality. Animal Behaviour 31: 814-826.

Biben M. 1989. Effects of social environment on play in squirrel monkeys (Saimiri sciureus): resolving Harlequin's dilemma. Ethology 81:72-82.

Biben M. 1998. Squirrel monkey playfighting: making the case for a cognitive training function for play. Pages 161-182 in Animal Play: Evolutionary, Comparative and Ecological Perspectives, edited by $\mathrm{M}$ Bekoff and J A Byers. Cambridge: Cambridge University Press.

Biben M, Symmes D, Bernhards D. 1989. Vigilance during play in squirrel monkeys. American Journal of Primatology 17:41-49.

Bjorklund D F, Brown R D. 1998. Physical play and cognitive development: integrating activity, cognition, and education. Child Development 69: 604-606.

Breuggeman J A. 1978. The function of adult play in free-ranging Macaca mulatta. Pages 169-191 in Social Play in Primates, edited by E O Smith. New York: Academic Press.

Burghardt G M. 1984. On the origins of play. Pages 6-41 in Play in Animals and Humans, edited by $\mathrm{P}$ K Smith. Oxford: Basil Blackwell.

Burghardt G M. 1988. Precocity, play, and the ectotherm endotherm transition-profound reorganization or superficial adaptation? Pages 107148 in Handbook of Behavioral Neurobiology, edited by E M Blass. New York: Plenum Publishing.

Burghardt G M. 1998a. The evolutionary origins of play revisited: lessons from turtles. Pages 1-26 in Animal Play: Evolutionary, Comparative and Ecological Perspectives, edited by M Bekoff and J A Byers. Cambridge: Cambridge University Press.

Burghardt G M. 1998b. Play. Pages 725-735 in Comparative Psychology: A Handbook, edited by G Greenberg and M M Haraway. New York: Garland Publishing.

Burghardt G M. 1999. Conceptions of play and the evolution of animal minds. Evolution and Cognition 5:115-123.

Byers J A. 1977. Terrain preferences in the play behaviour of Siberian ibex kids. Zeitschrift Für Tierpsychologie 45:199-209.

Byers J A. 1980. Play partner preferences in Siberian ibex, Capra ibex siberica. Zeitschrift Für Tierpsychologie 53:23-40.

Byers J A. 1984. Play in ungulates. Pages 43-65 in Play in Animals and Humans, edited by P K Smith. Oxford: Basil Blackwell.

Byers J A. 1998. Biological effects of locomotor play: getting into shape, or something more specific? Pages 205-220 in Animal Play: Evolutionary, Comparative and Ecological Perspectives, edited by $\mathrm{M} \mathrm{Be}-$ koff and J A Byers. Cambridge: Cambridge University Press.

Byers J A. 1999. The distribution of play behaviour among Australian marsupials. Journal of Zoology 247:349-356.

Byers J A, Walker C. 1995. Refining the motor training hypothesis for the evolution of play. American Naturalist 146:25-40.

Caro T M. 1980. The effects of experience on the predatory patterns of cats. Behavioral and Neural Biology 29:1-28.

Caro T M. 1988. Adaptive significance of play: are we getting closer. Trends in Ecology Ẽ Evolution 3:50-53.

Chalmers N R, Locke-Haydon J. 1984. Correlations among measures of playfulness and skillfulness in captive common marmosets (Callithrix jacchus jacchus). Developmental Psychobiology 17:191-208.

Coppinger R P, Smith C K. 1989. A model for understanding the evolution of mammalian behavior. Pages 335-374 in Current Mammalogy, edited by H Genoways. New York: Plenum Press.

Curio E. 1994. Causal and functional questions: how are they linked? Animal Behaviour 47:9991021.

da Silva N L, Ferreira V M M, Carobrez A D, Morato GS. 1996. Individual housing from rearing modifies the performance of young rats on the elevated plus-maze apparatus. Physiology $\mathcal{E}^{2}$ Behavior 60:1391-1396.

Dawkins M S. 1990. From an animal's point of view-motivation, fitness, and animal welfare. Behavioral and Brain Sciences 13:1-61.

de Passillé A M, Rushen J, Martin F. 1995. Interpreting the behaviour of calves in an open-field test: a factor analysis. Applied Animal Behaviour Science 45:201-213.

de Waal F. 1996. Good Natured: The Origins of Right and Wrong in Humans and Other Animals. Cambridge (MA): Harvard University Press.

Dobao M T, Rodriganez J, Silio L. 1985. Choice of companions in social play in piglets. Applied Animal Behaviour Science 13:259-266. 
Drea C M, Hawk J E, Glickman S E. 1996. Aggression decreases as play emerges in infant spotted hyaenas: preparation for joining the clan. Animal Behaviour 51:1323-1336.

Einon D F, Morgan M J, Kibbler C C. 1978. Brief periods of socialization and later behavior in the rat. Developmental Psychobiology 11:213-225.

Eisenberg J F. 1981. The Mammalian Radiations: An Analysis of Trends in Evolution, Adaptation, and Behavior. Chicago: University of Chicago Press.

Enomoto T. 1990. Social play and sexual behavior of the bonobo (Pan paniscus) with special reference to flexibility. Primates 31:469-480.

Fagen R. 1981. Animal Play Behavior. Oxford: Oxford University Press.

Fagen R M, George T K. 1977. Play behavior and exercise in young ponies (Equus caballus). Behavioral Ecology and Sociobiology 2:267-269.

Fontaine R P. 1994. Play as physical flexibility training in five ceboid primates. Journal of Comparative Psychology 108:203-212.

Fraser D, Duncan I J H. 1998. "Pleasures", "pains" and animal welfare: toward a natural history of affect. Animal Welfare 7:383-396.

Geist V. 1963. On the behaviour of the North American moose (Alces alces andersoni Petrason 1950) in British Columbia. Behaviour 20:378-415.

Gentry R L. 1974. The development of social behavior through play in the Stellar sea lion. American Zoologist 14:391-403.

Gentsch C, Lichtsteiner M, Frischknecht H R, Feer H, Siegfried B. 1988. Isolation-induced locomotor hyperactivity and hypoalgesia in rats are prevented by handling and reversed by resocialization. Physiology Eं Behavior 43:13-16.

Golani I. 1992. A mobility gradient in the organization of vertebrate movement: the perception of movement through symbolic language. Behavioral and Brain Sciences 15:249-266.

Gomendio M. 1988. The development of different types of play in gazelles-implications for the nature and functions of play. Animal Behaviour 36:825-837.

Groos K. 1898. The Play of Animals. New York: D. Appleton.

Hall S L. 1998. Object play by adult animals. Pages 45-60 in Animal Play: Evolutionary, Comparative andEcological Perspectives, edited by $\mathrm{M}$ Bekoff and JA Byers. Cambridge: Cambridge University Press.

Haynes M R. 1997. Play behavior in juvenile domestic cattle (Bos taumus): sex differences and developmental changes. [Masters Thesis]. College Park (MD): University of Maryland.

Holmes W G. 1994. The development of littermate preferences in juvenile Belding's ground squirrels. Animal Behaviour 48:1071-1084.

Hol T, van den Berg C L, van Ree J M, Spruijt B M. 1999. Isolation during the play period in infancy decreases adult social interactions in rats. Behavioral Brain Research 100:91-97.

Inhelder E. 1955. Object play in an Indian rhino (Rhinoceros unicornis). Zeitschrift Für Tierpsychologie 12:88-144.

Jensen M B, Vestergaard K S, Krohn C C. 1998. Play behaviour in dairy calves kept in pens: the effect of social contact and space allowance. Applied Animal Behaviour Science 56:97-108.

Jerison H. 1973. Evolution of Brain and Intelligence. New York: Academic Press.

Jouvet M. 1998. Paradoxical sleep as a programming system. Journal of Sleep Research 7 Supplement 1:1-5.

Knutson B, Burgdorf J, Panksepp J. 1998. Anticipation of play elicits high frequency ultrasonic vocalizations in young rats. Journal of Comparative Psychology 112:65-73.

Loranca A, Torrero C, Salas M. 1999. Development of play behavior in neonatally undernourished rats. Physiology $\mathcal{E}^{2}$ Behavior 66:3-10.

Lund J D, Vestergaard K S. 1998. Development of social behaviour in four litters of dogs (Canis familiaris). Acta Veterinaria Scandinavica 39:183-193.

Markus N, Croft D B. 1995. Play behaviour and its effects on social development of common chimpanzees (Pan troglodytes). Primates 36:213-225.

Martin P. 1984. The time and energy costs of play behaviour in the cat. ZeitschriftFür Tierpsychologie 64:298-312.

Martin P, Bateson P. 1985. The influence of experimentally manipulating a component of weaning on the development of play in domestic cats. $A n$ imal Behaviour 33:511-518.

Meaney M J, Steward J, Beatty W W. 1985. Sex differences in social play: the socialization of sex roles. Pages 1-58 in Advances in the Study of Behaviour, Volume 15, edited by J S Rosenblatt et al. New York: Academic Press.

Mendoza-Granados D, Sommer V. 1995. Play in chimpanzees of the Arnhem zoo-self-serving compromises. Primates 36:57-68.

Miller M N, Byers J A. 1998. Sparring as play in young pronghorn males. Pages 141-160 in Animal Play: Evolutionary, Comparative and Ecological Perspectives, edited by M Bekoff and J A Byers. Cambridge: Cambridge University Press.

Mirmiran M. 1995. The function of fetal/neonatal rapid eye movement sleep. Behavioural Brain $R e^{-}$ search 69:13-22.

Møller A P. 1998. Developmental instability as a general measure of stress. Pages 181-213 in Advances in the Study of Behavior, Volume 27: Stress and Behavior, edited by A P Møller, M Milinski, and P J B Slater. San Diego (CA): Academic Press. Moss C. 1988. Elephant Memories: Thirteen Years in the Life of an Elephant Family. New York: Fawcett Columbine. 
Müller-Schwartze D. 1968. Play deprivation in deer. Behaviour 31:144-162.

Newberry R C, Wood-Gush D G M. 1988. Development of some behaviour patterns in piglets under semi-natural conditions. Animal Production 46: 103-109.

Newberry R C, Wood-Gush D M G, Hall J W. 1988. Playful behaviour of piglets. Behavioural Processes 17:205-216.

Ortega J C, Bekoff M. 1987. Avian play: comparative evolutionary and developmental trends. Auk 104: 338-341.

Owens N W. 1975. A comparison of aggressive play and aggressions in free-living baboons Papio anubis. Animal Behaviour 23:755-765.

Panksepp J. 1998. Affective Neuroscience: The Foundations of Human and AnimalEmotions. Oxford: Oxford University Press.

Parisi D, Nolfi S. 1996. The influence of learning on evolution. Pages 419-428 in Adaptive Individuals in Evolving Populations: Models and Algorithms, edited by R K Belew and M Mitchell. Reading (MA): Addison-Wesley.

Pedersen J M, Glickman S E, Frank L G, Beach F A. 1990. Sex differences in the play behavior of immature spotted hyenas, Crocuta crocuta. Hormones and Behavior 24:403-420.

Pellegrini A D. 1995. Boys' rough-and-tumble play and social competence: contemporaneous and longitudinal relations. Pages 107-126 in The Future of Play Theory: A Multidisciplinary Inquiry into the Contributions of Brian Sutton-Smith, edited by A D Pellegrini. Albany (NY): State University of New York Press.

Pellegrini A D, Smith P K. 1998. Physical activity play: the nature and function of a neglected aspect of playing. Child Development 69:577-598.

Pellis S M. 1993. Sex and the evolution of play fighting: a review and model based on the behavior of muroid rodents. Play Theory Research 1:55-75.

Pellis S M, Pellis V C. 1983. Locomotor-rotational movements in the ontogeny and play of the laboratory rat Rattus norvegicus. Developmental Psychobiology 16:269-286.

Pellis S M, Pellis V C. 1991. Role reversal changes during the ontogeny of play fighting in male rats: attack vs. defense. Aggressive Behavior 17: 179-189.

Pellis S M, Pellis V C, McKenna M M. 1993. Some subordinates are more equal than others: play fighting amongst adult subordinate male rats. Aggressive Behavior 19:385-393.

Pereira M E, Preisser M C. 1998. Do strong primate players "self-handicap" during competitive social play? Folia Primatologica 69:177-180.

Potegal M, Einon D. 1989. Aggressive behaviors in adult rats deprived of playfighting experience as juveniles. Developmental Psychobiology 22:159-172.

Power T G. 2000. Play and Exploration in Children and Animals. New York: Lawrence Erlbaum.
Prescott J. 1985. Play and the development of individual and social behavior in the American bison (Bison bison). Biology of Behaviour 10:261-276.

Rasa O A E. 1984. A motivational analysis of object play in juvenile dwarf mongooses (Helogale undulata rufula). Animal Behaviour 32:579-589.

RenoufD. 1993. Play in a captive breeding colony of harbour seals (Phoca vitulina)-constrained by time or by energy. Journal of Zoology 231:351-363.

Ribeiro S, Goyal V, Mello C V, Pavlides C. 1999. Brain gene expression during REM sleep depends on prior waking experience. Learning and Memory 6:500-508.

Rothstein A, Griswold J G. 1991. Age and sex preferences for social partners by juvenile bison bulls, Bison Bison. Animal Behaviour 41:227-237.

Sade D S. 1973. An ethogram for rhesus monkeys. I. Antithetical contrast in posture and movement. American Journal of Physical Anthropology 38:537542.

Saunders I, Sayer M, Goodale A. 1999. The relationship between playfulness and coping in preschool children: a pilot study. American Journal of Occupational Therapy 53:221-226.

Siegel J M. 1995. Phylogeny and the function of REM sleep. Behavioural Brain Research 69:29-34.

Siegel J M, Manger P R, Nienhuis R, Fahringer H M, PettigrewJ D. 1998. Monotremes and the evolution of rapid eye movement sleep. Philosophical Transactions of the Royal Society of London B 353: 1147-1157.

Siviy S M. 1998. Neurobiological substrates of play behavior: glimpses into the structure and function of mammalian playfulness. Pages 221-242 in Animal Play: Evolutionary, Comparative and Ecological Perspectives, edited by M Bekoff and J A Byers. Cambridge: Cambridge University Press.

Smith L K, Forgie M L, Pellis S M. 1998. Mechanisms underlying the absence of the pubertal shift in the playful defense of female rats. Developmental Psychobiology 33:147-156.

Sommer V, Mendoza-Granados D. 1995. Play as indicator of habitat quality: a field study of langur monkeys (Presbytis entellus). Ethology 99:177-192.

Spencer H. 1898. The Principles of Psychology. New York: Appleton.

Spijkerman R P, Dienske H, van Hooff J A R A M, Jens W. 1996. Differences in variability, interactivity and skills in social play of young chimpanzees living in peer groups and in a large family zoo group. Behaviour 133:717-739.

Stamps J. 1995. Motor learning and the value of familiar space. American Naturalist 146:41-58.

Thompson K V. 1996. Play-partner preferences and the function of social play in infant sable antelope, Hippotragus niger. Animal Behaviour 52: 1143-1155. 
Thompson K V. 1998. Self assessment in juvenile play. Pages 183-204 in Animal Play: Evolutionary, Comparative and Ecological Perspectives, edited by $M$ Bekoff and J A Byers. Cambridge: Cambridge University Press.

Tobler I. 1995. Is sleep fundamentally different between mammalian species? Behavioral and Brain Sciences 69:35-41.

van den Berg C L, Hol T, van Ree J M, Spruijt B M, Everts H, Koolhaas J M. 1999a. Play is indispensable for an adequate development of coping with social challenges in the rat. Developmental Psychobiology 34:129-138.

van den Berg C L, van Ree J M, Spruijt B M. 1999b. Sequential analysis of juvenile isolation-induced decreased social behavior in the adult rat. Physiology and Behavior 67:483-488.

van den Berg C L, van Ree J M, Spruijt B M, Kitchen I. 1999c. Effects of juvenile isolation and morphine treatment on social interactions and opioid receptors in adult rats: behavioural and autoradiographic studies. European Journal of Neuroscience 11:3023-3032.

Vanderschuren L J M J, Niesink R J M, Spruijt B M, van Ree J M. 1995a. Influence of environmental factors on social play behavior of juvenile rats. Physiology and Behavior 58:119-123.

Vanderschuren L J M J, Niesink R J M, Spruijt B M, van Ree J M. 1995b. $\mu$ - and $\kappa$-opioid receptormediated opioid effects on social play in juvenile rats. European Joumal of Pharmacology 276:257-266.

Vanderschuren LJ M J, Niesink R J M, van Ree J M. 1997. The neurobiology of social play-behavior in rats. Neuroscience and Biobehavioral Reviews 21: 309-326.
Vertes R P. 1986. A life-sustaining function for REM sleep: a theory. Neuroscience and Biobehavioral Reviews 10:371-376.

von Holst D. 1998. The concept of stress and its relevance for animal behavior. Pages 1-131 in Advances in the Study of Behavior, Volume 27: Stress and Behavior, edited by A P Møller, M Milinski, and PJ B Slater. San Diego (CA): Academic Press.

Watson D M. 1998. Kangaroos at play: play behaviour in the Macropodoidea. Pages 61-95 in Animal Play: Evolutionary, Comparative and Ecological Perspectives, edited by M Bekoff and J A Byers. Cambridge: Cambridge University Press.

Watson D M, Croft D B. 1996. Age-related differences in playfighting strategies of captive male red-necked wallabies (Macropus rufogriseus banksianus). Ethology 102:336-346.

Wehr T A. 1992. A brain-warming function for REM sleep. Neuroscience and Biobehavioral Reviews 16: 379-397.

Willford J A, Segar T M, Barron S. 1999. The behavioral response to novelty is altered in rats neonatally exposed to cocaine. Developmental Psychobiology 35:343-351.

Wilson S G, Kleiman D G. 1974. Eliciting play: a comparative study. American Zoologist 14:341-370.

Winson J. 1993. The biology and function of rapid eye movement sleep. Current Opinion in Neurobiology 3:243-248.

Wood-Gush D G M, Vestergaard K. 1991. The seeking of novelty and its relation to play. Animal Behaviour 42:599-606.

Zucker E L, Dennon M B, Puleo S G, Maple T L. 1986. Play profiles of captive adult orangutans: a developmental perspective. Developmental Psychobiology 19:315-326. 